\title{
ELECTRONIC CONTROL OF CELL CULTURES USING CONJUGATED POLYMER SURFACES
}

\author{
Kristin Persson
}

Norrköping 2014 


\section{Electronic Control of Cell Cultures Using Conjugated Polymer Surfaces}

\section{Kristin Persson}

During the course of the research underlying this thesis, Kristin Persson was enrolled in Forum Scientium, a multidisciplinary doctoral programme at Linköping University, Sweden

Linköping Studies in Science and Technology. Dissertation No. 1594

Copyright (C) Kristin Persson 2014 unless otherwise noted

Printed by LiU-Tryck, Linköping 2014

ISBN: 978-91-7519-340-3

ISSN: 0345-7524

Electronic publication: http://www.ep.liu.se 


\section{ABSTRACT}

In the field of bioelectronics various electronic materials and devices are used in combination with biological systems in order to create novel applications within cell biology and medicine. A famous example of a successful bioelectronics application is the pacemaker. Metals are the most common electrical conductors, whereas polymers are generally considered being insulators. However, in the late 1970s it was shown that a special class of polymers with conjugated double bonds, could in fact, after some chemical modifications, conduct electricity. This was the start of the research field known as conducting polymers, and then later on organic electronics, a research area that has grown rapidly during the last decades. Conjugated polymers are also suitable to interact and interface with cells and tissues, as they are generally soft, flexible and biocompatible. In addition, their chemical properties can be tailor-made through synthesis to fit biological requirements and functions. During the last years applications using organic bioelectronics have become numerous.

This thesis describes applications based on different conjugated polymers aiming to stimulate and control cell cultures. When culturing cells it is of interest to be able to control events such as adhesion, spreading, proliferation, differentiation and detachment. First, the impact of different polymer compositions and redox states on the adhesion of bacteria and subsequent biofilm formation was investigated. Similar polymer electrodes were also used to steer differentiation of neural stem cells, through changes in the surface exposure of a relevant biomolecule. Controlled delivery of molecules was achieved by coating nanoporous membranes with polymers that swell and contract when changing the redox state. Finally, electronic control over cell detachment using a water-soluble polymer was achieved. When applying a positive potential to this polymer, it swells, cracks and finally detaches, taking the cells that was cultured on top along with it. Together, the work and results presented in this thesis demonstrate a versatile conjugated polymer technology to achieve electronic control of the different growth stages of cell cultures as well as cellular functions. 


\section{POPULÄRVETENSKAPLIG SAMMANFATTNING}

Olika plaster finns numera överallt omkring oss och utgör ett av de absolut vanligaste materialen i vår vardag. Även elektronik har blivit en naturlig del av vår tillvaro och finns i en mängd olika produkter. Inom medicinsk teknik kommer allt fler applikationer som innefattar elektronik, ett exempel är pacemakern. Arbetet som ligger till grund för denna avhandling strävar efter att kombinera plaster och elektronik för tillämpningar inom medicin och cellbiologi.

Plaster består till största delen av polymerer samt olika tillsatser för att få ett material med önskade egenskaper. Polymerer är i sin tur uppbyggda av långa kedjor av identiska molekylära byggstenar, så kallade monomerer. Monomerens kemi och struktur bestämmer även egenskaperna hos polymeren. Med hjälp av organisk kemi kan monomerer med speciella egenskaper syntetiseras och på så sätt kan vi skräddarsy polymerer för olika tillämpningar och produkter.

Vanligtvis är plaster isolerande material, men i slutet av 1970-talet visade Alan Heeger, Alan McDiarmid och Hideki Shirakawa att vissa polymerer även kan leda elektrisk ström. Detta var starten på forskningsområdet ledande polymerer och organisk elektronik. De tre forskarna fick nobelpriset i kemi år 2000 för sina upptäckter. Ledningsförmågan hos dessa polymerer beror på att de är konjugerade i sin elektroniska struktur, vilket innebär att dubbel- och enkelbindningar alterneras längs med polymerkedjan. Laddningsbärare kan därmed enkelt transporteras genom materialet. Genom olika kemiska processer som gemensamt kallas dopning kan ledningsförmågan hos polymererna förbättras avsevärt och i vissa fall kan till och med metalliska egenskaper uppnås. Organisk elektronik har använts bland annat för displayer, solceller och transistorer. Polymererna har dessutom egenskaper som gör dem tryckbara, och tryck elektronik är ett användningsområde som förväntas växa då massproduktion av elektronik till en låg kostnad möjliggörs.

Intresset för att kombinera biologi och elektronik i så kallade bioelektroniska applikationer går långt tillbaka. Polymerer är, jämfört med metaller, mjuka, flexibla och lätta att modifiera kemiskt, vilket gör dem lämpliga att använda för dessa bioelektroniska tillämpningar inom biologi och medicin. Organisk bioelektronik är därför ett växande forskningsområde, och det finns en mängd tillämpningar. 
Exempelvis kan sensorer, frisättning av läkemedel och polymerelektroder för stimulering av celler nämnas.

Den här avhandlingen beskriver elektronisk kontroll av cellodlingar med hjälp av organisk elektronik. Celler har odlats på ytor bestående av olika ledande polymerer och därefter stimulerats med elektriska impulser. Genom att använda polymerer med olika egenskaper och variera den pålagda elektriska spänningen kan elektroaktiva cellodlingsytor med olika specifika funktioner framställas. Inledningsvis behandlas hur adhesion av bakterier till dessa ytor beror på den kemiska sammansättningen i kombination med spänningens polaritet. Därefter visas att specialisering av stamceller också kan styras av en elektroaktiv yta. Dessutom behandlas transport av molekyler genom ett membran täckt med olika ledande polymerer. Den senare delen av avhandlingen behandlar frisläppning av celler från den yta där de odlats. Detta sker med hjälp av en elektroaktiv vattenlöslig polymer som spricker upp och lossnar, då en positiv elektrisk spänning läggs på, och därmed tar med sig cellerna som odlats ovanpå den. 


\section{ACKNOWLEDGEMENTS}

This thesis, and all the work I have done during my $\mathrm{PhD}$-studies, would not have possible without the help and support from the people around me. I would like to express my gratitude to:

Magnus Berggren, my main supervisor, for giving me the opportunity to join the inspiring environment of the Organic Electronics group, and for your never ending enthusiasm and creativity and for giving me the freedom to pursue my own ideas

Edwin Jager, my first co-supervisor, for introducing me to the field of organic bioelectronics and for a lot of practical help in the lab

Peter Konradsson, my second co-supervisor, for lots of interesting discussions and for having the solutions to any chemical problems

Sophie Lindesvik, for all your great help on administrative issues and for having the answer to just about everything

Lars Gustavsson and Bengt Råsander, for keeping the lab in great shape

Daniel Simon, for all the challenging scientific discussions and for your great help on any computer (Mac)-related issues

All co-authors and collaborators, for your expertise in areas different than mine, this multi-disciplinary research wouldn't have been possible without you! In particular I would like to thank Roger Gabrielsson, for synthesizing endless amounts of polymer, and the cell experts Karl Svennersten, Susanna Lönnqvist and Anna Herland for testing my devices with cells. 
All past and present members of the Organic Electronics group for your friendship, stimulating discussions and for creating such a nice work environment. Thanks for all the good times we have had both in and outside the office! In particular I would like to thank Anders, Amal, Henrik and Amanda, for the great atmosphere in the office over the years. Lars and Oscar, for all fun discussions and for joining me at Lidingöloppet. Klas, for making the best breakfast, all the fun we have had and also for all your invaluable help regarding scientific problems. Maria, for introducing me to the field, for your positive attitude and all the good times we have shared over the years.

All the staff at Acreo for creating such a nice work atmosphere in the new office. In particular David Nilsson for all your help and valuable discussions, and Anurak Sawatdee for your input in the lab.

Forum Scientium and Stefan Klintström for all the great research trips

Friends and family, for your support, friendship and all the good times and many laughs we have shared over the years

My mum, dad and sister for your love and support, even though you don't have a clue what I'm doing most of the time

Andreas for your love, support and patience and for always believing in me. Arvid, for making me smile and forget everything else, and for making sure I always get up in the morning!

TACK! 


\section{LIST OF INCLUDED PAPERS}

\section{Paper I}

Salmonella Biofilm Modulation with Electrically Conducting Polymers

S. Gomez-Carretero, K. Persson, B. Libberton, K. Svennersten, M. Berggren, M. Rhen, A. Richter-Dahlfors

Manuscript

Contribution: Device design, initial fabrication and material characterisation, wrote parts of the first draft of the manuscript

\section{Paper II}

Electrochemical Control of Growth Factor Presentation to Steer Neural Stem Cell Differentiation

A. Herland, K. M. Persson, V. Lundin, M. Fahlman, M. Berggren, E. W. H. Jager, A. I. Teixeira

Angew. Chem. Int. Ed. 2011, 50, 12529-12533

Contribution: All experimental work on the material side, wrote parts of the first draft of the manuscript

\section{Paper III}

Electroresponsive Nanoporous Membranes by Coating Anodized Alumina with Poly(3,4- ethylenedioxythiophene) and Polypyrrole

A. E. Abelow, K. M. Persson, E. W. H. Jager, M. Berggren, I. Zharov Macromol. Mater. Eng. 2014, 299, 190-197

Contribution: Preparation and analysis of polymer coated membranes, wrote the first draft of the manuscript together with the other authors 


\section{Paper IV}

\section{Electronic Control of Cell Detachment Using a Self-Doped Conducting Polymer}

K. M. Persson, R. Karlsson, K. Svennersten, S. Löffler, E. W. H. Jager, A. RichterDahlfors, P. Konradsson, M. Berggren

Adv. Mater. 2011, 23, 4403-4408

Contribution: Device fabrication and electrical characterization, wrote the first draft of the manuscript with the other authors, and contributed to the final editing

\section{Paper V}

Electronic Control over Detachment of a Self-Doped Water-Soluble Conjugated Polyelectrolyte

K. M. Persson, R. Gabrielsson, A. Sawatdee, D. Nilsson, P. Konradsson, M.

Berggren

Submitted

Contribution: Most of the experimental work, wrote major part of the first draft of the manuscript and contributed to the final editing

\section{Paper VI}

\section{Selective Detachment of Human Primary Keratinocytes and} Fibroblasts Using an Addressable Conjugated Polymer Matrix

K. M. Persson, S. Lönnqvist, K. Tybrandt, R. Gabrielsson, D. Nilsson, G. Kratz, M. Berggren

Manuscript

Contribution: All experimental work on the material side, wrote major part of the first draft of the manuscript and contributed to the final editing 


\section{RELATED WORK NOT INCLUDED IN THE THESIS}

\section{Patent application}

A device comprising a conductive surface and a conductive polymer for adhesion of cells and tissue

EP 2556153 A2 


\section{TABLE OF CONTENTS}

1. INTRODUCTION ....................................................................... 1

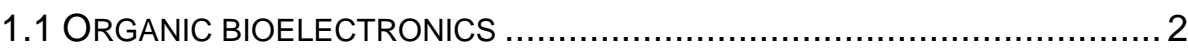

1.2 AIM AND OUTLINE OF THE THESIS ............................................. 2

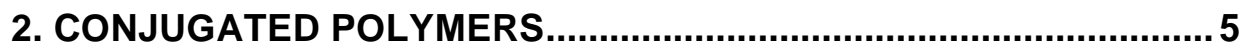

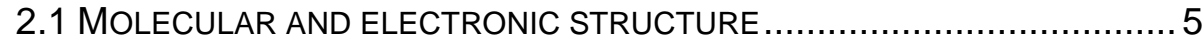

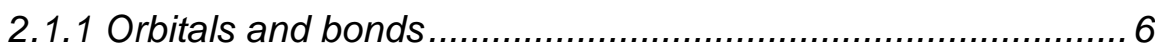

2.1.2 Origin of conductivity....................................................... 9

2.2 CHARGE CARRIERS AND CHARGE TRANSPORT ............................... 11

2.2.1 Solitons ...................................................................... 11

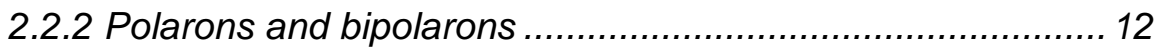

2.2.3 Charge transport........................................................... 12

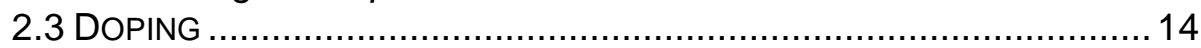

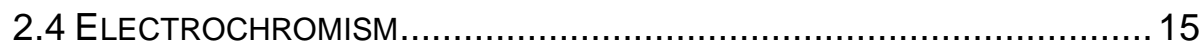

2.5 DIFFERENT CONJUGATED POLYMERS ....................................... 16

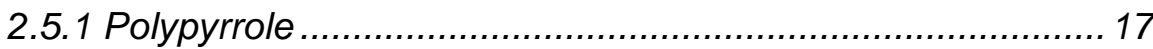

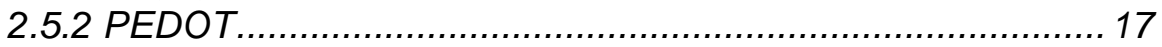

2.5.3 PEDOT-S ....................................................................... 18

3. ELECTROCHEMISTRY................................................................ 19

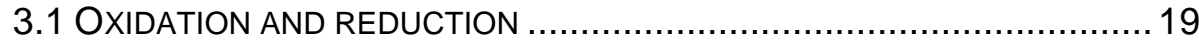

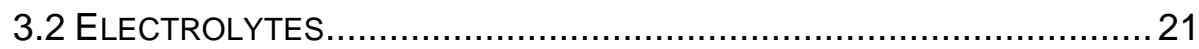

3.2.1 Different electrolytes ........................................................ 21

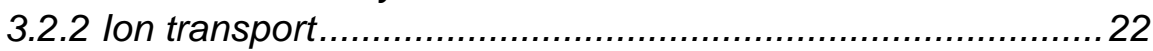

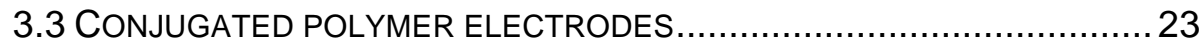

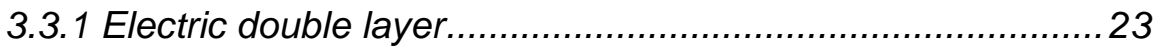

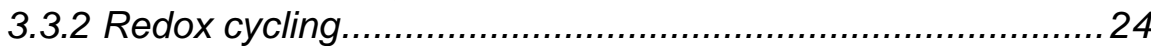

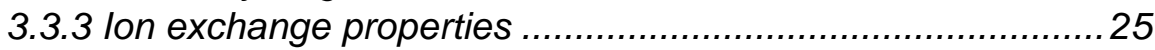

3.4 ELECTROCHEMICALLY INDUCED CHANGES .................................. 25

3.4.1 Surface energy and composition ................................... 25

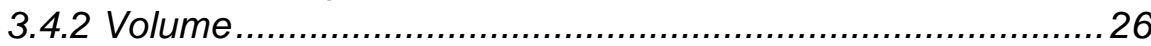

4. ORGANIC BIOELECTRONICS .................................................... 29

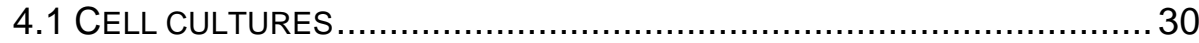

4.1.1 Cell signalling and communication................................... 30

4.2 PROTEIN ADSORPTION TO POLYMER ELECTRODES........................... 31

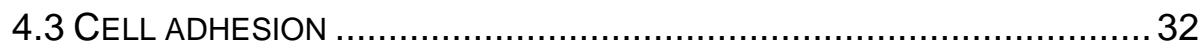


4.4 STIMULATION AND CONTROL OF CELLS IN CULTURE ........................ 33

4.4.1 Chemical stimulation......................................................... 33

4.4.2 Stimulation through the substrate .................................... 34

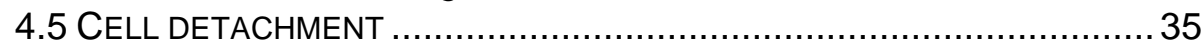

4.6 STRUCTURE AND ADHESION OF BACTERIA ................................. 36

4.6.1 Biofilm formation .......................................................... 37

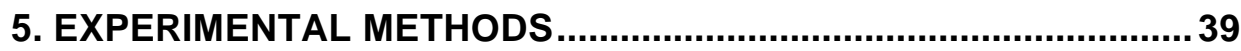

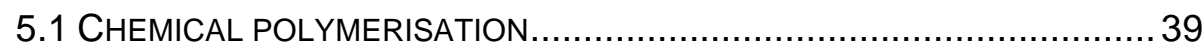

5.1.1 Vapour phase polymerisation ......................................... 40

5.2 ELECTROCHEMICAL METHODS ................................................. 41

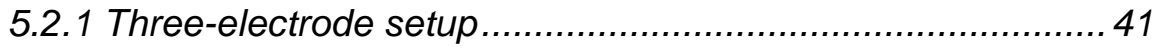

5.2.2 Electropolymerisation ..................................................... 42

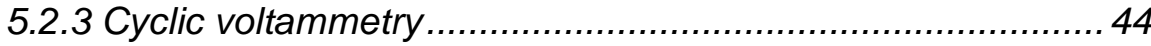

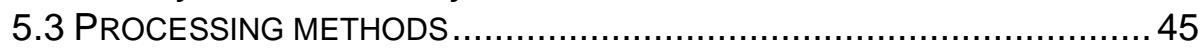

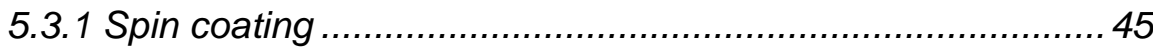

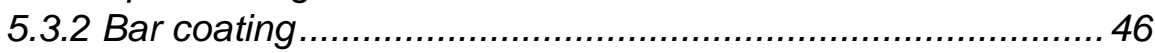

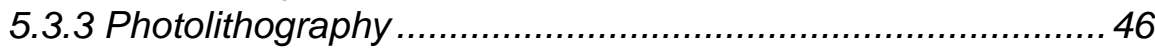

5.3.4 Subtractive techniques.................................................. 47

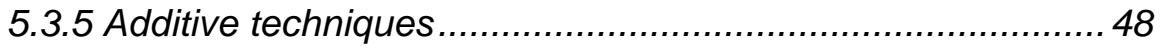

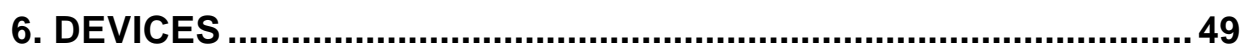

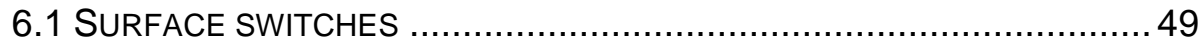

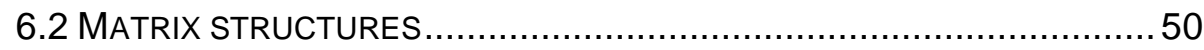

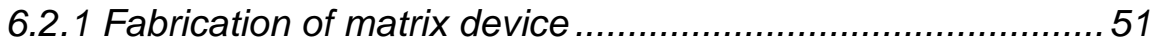

7. CONCLUSIONS AND FUTURE OUTLOOK ................................... 53

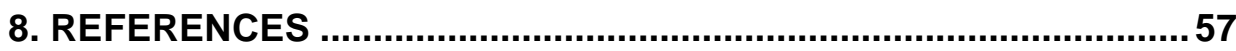


PART 1

\section{BACKGROUND}





\section{INTRODUCTION}

In the $19^{\text {th }}$ century electricity began to be utilized at large scale, it was of great importance during the industrial revolution and also improved the quality of daily life for millions of people. In 1947 the first transistor was constructed by John Bardeen and Walter Brattain, starting the era of modern electronics. ${ }^{[1]}$ In 1956 Bardeen and Brattain were together with William Shockley awarded the Nobel Prize in Physics for their discoveries in the field of inorganic semiconductors. Today it is hard to imagine a life without electricity and electronic (transistor based) devices. Typical electric conductors are metals and alloys, and semiconductors like silicon and germanium are widely used in transistors.

Contrary to metals and semiconductors, plastic materials are generally regarded as electric insulators. Plastics are composed mainly of polymers and different additives. Polymers in turn consist of small identical building blocks called monomers, arranged in long chains. Natural polymers like rubber have been used for a long time but it was not until the early $20^{\text {th }}$ century that synthetic plastics were first developed, one of the first applications was as the insulating material used around electric wires. Polymers can be chemically tailor-made to posses a range of different properties, making plastics extremely versatile as technological materials in industrial and consumer applications. In the 1950s the industrial production of plastics exploded, and many traditional materials like wood, glass and textiles were then replaced. Today plastics are, just as electronics, an essential part of our everyday life.

In the late 1970s it was discovered that certain polymers that are built up from alternating single and double bonds, known as conjugated polymers, could become electronic conductors after chemical modifications referred to as doping. ${ }^{[2,3]}$ This was the beginning of the research area today known as conducting polymers and later on as organic electronics. In the year 2000, Alan J. Heeger, Alan G. MacDiarmid and Hideki Shirakawa were awarded the Nobel Prize in Chemistry for their ground-breaking work in conducting polymers. Today there are several applications based on organic electronics, including anti-static photographic films, smart windows and displays based on organic light-emitting diodes (OLED). There is also a considerable amount of research employing 
conjugated polymers in applications such as organic solar cells, ${ }^{[4]}$ thin film transistors $^{[5]}$ and sensors. ${ }^{[6]}$ In addition, as conjugated polymers can be manufactured from solution it is possible to enable low-cost and high volume manufacturing with printing processes.

\subsection{Organic bioelectronics}

In the early days of electricity, a lot of different experiments were performed in order to understand its possible uses. In 1771 Luigi Galvani discovered that an electric signal could make the legs of a dead frog move. Galvani's experiment can be viewed as an early attempt of bioelectronics. Since then, scientists have continued to combine electricity and biology, for example to stimulate and record signals from neurons. Another well-known example is the pacemaker, which today saves the lives of many patients suffering from heart arrhythmia.

Conjugated polymers have a number of features that make them suitable as the signal translator in bioelectronics, either to record or transmit signals. They are soft, flexible, transparent and biocompatible, and are in addition both electronically and ionically conducting. Applications employing organic bioelectronics include drug release, ${ }^{[7]}$ neuronal electrodes, ${ }^{[8]}$ active surfaces for control of cell adhesion ${ }^{[9]}$ and precise delivery of ions and pharmaceuticals. ${ }^{[10]}$

\subsection{Aim and outline of the thesis}

To control the different stages during the cell's lifecycle is in many cases desired when cells are cultivated. The different stages of an in vitro cell growth process are seeding, adhesion, followed by spreading and proliferation. In the case of stem cells, control of differentiation is of particular importance. In many applications it is also of interest to be able to actively detach cells after sufficient time in culture, making cell detachment yet another parameter to control. There are many ways to achieve required control of growth stages, techniques that often involve addition of various chemical agents to the cell growth media or directly onto the cell culture dish through proper immobilization. The main drawback when using such chemical procedures is that they typically lack precision in terms of spatiotemporal resolution. If conjugated polymers are instead used as cell culture substrates, changes can be induced through electronic signals. As the polymers in question often can be patterned into microstructures it is possible to achieve highly local modulation of cell culture events at a specific point in time. 
Previous work in our group focused mainly on the control of the cell adhesion properties through changes in the redox state of a conjugated polymer surface. ${ }^{[11,12]}$ The aim of this thesis has been to further explore the use of conjugated polymers to achieve electronic control of cells during cultivation. This has been achieved by tailor-made polymer synthesis and by the incorporation of biologically active molecules to influence adhesion of cells and bacteria and also differentiation of stem cells. Further, I have aimed to find a polymer suitable for control of cell detachment. Improving our ability to control and modulate a cell culture will have an impact in for example tissue engineering, with the stretch goal of creating artificial tissue and organs.

The first part of the thesis serves as an introduction to provide the necessary background in order to understand the scientific results in the papers presented in the second part. Topics such as the properties of conjugated polymers and the materials used are briefly described, followed by chapters treating electrochemistry, organic bioelectronics and the specific experimental methods and devices used in the papers.

The second part of the thesis includes the six papers, presenting the major results of the thesis.

Papers I - III all focus on changes in the surface properties induced by a switch in redox state of the polymers used. In Paper I conjugated polymer electrodes doped with different biologically relevant molecules and in different redox states were used to achieve control of bacterial adhesion and subsequent biofilm formation. In Paper II electrodes, similar to the ones used in Paper I, were modulated to interact with growth factors, in turn steering differentiation of neural stem cells. By a change in the redox state of the polymer the expression of a growth factor was altered, dictating the fate of the cells. In Paper III nanoporous membranes coated with conjugated polymers were explored for active control of transport. The changes in the transport rate of the studied molecules depending on redox state of the polymer were evaluated.

The work presented in papers IV - VI focused on cell detachment, achieved through a water-soluble conjugated polymer. In Paper IV successful detachment of human epithelial cells was enabled. The electroactive detachment method was evaluated and compared to traditional ones. In Paper V, the detachment mechanism was investigated in more detail and in Paper VI a strategy to achieve spatial control of cell detachment, via matrix addressing, was realised. 


\section{CONJUGATED POLYMERS}

Organic molecules, like natural polymers, are mainly composed of carbon and hydrogen atoms and make up a large part of all living organisms. The number of existing polymers is huge and their properties vary a lot, from soft and flexible to hard and brittle, and from natural to synthetic. Natural polymers include for example DNA, cellulose and natural rubber. Synthetic polymers are used in a number of different areas to create various plastic materials; common examples are polyethylene terephthalate (PET) and polystyrene. Polymers are generally considered to be electrical insulators, however in some polymers the molecular structure gives rise to semiconducting and conducting properties. By further alterations of the properties of these polymers through doping, the conductivity can be increased to reach in some cases even metallic values of $10^{5} \mathrm{~S} / \mathrm{cm} .{ }^{[2]}$

\subsection{Molecular and electronic structure}

All matter is made of atoms, in turn composed of positively charged protons, neutral neutrons and negatively charged electrons (figure 2.1a). The carbon atom

a)

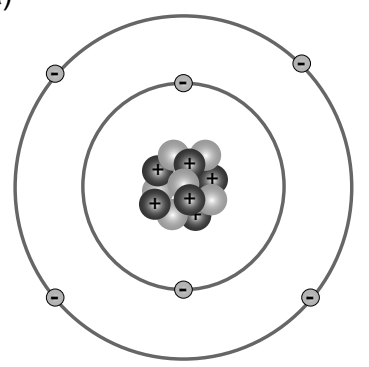

b)

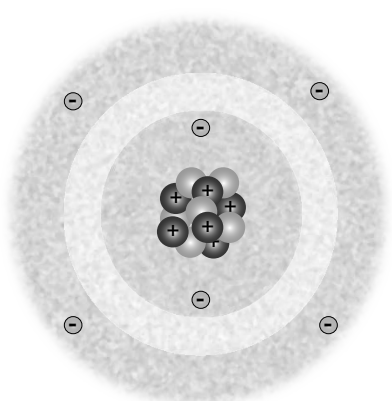

Figure 2.1 The carbon atom. In a), a schematic representation of the carbon atom including positively charged protons, neutral neutrons and negatively charged electrons is shown. In b) a model using electron clouds surrounding the nucleus is shown. The light field represents an area with lower electron density than the darker ones.

contains a nucleus with six protons and six neutrons surrounded by six electrons, two in the K-shell closest to the nucleus, and four in the outer L-shell, called valence electrons. In chemical compounds, the atoms are connected to each other 
by different bonds of different characteristics, depending on the electronegativity of the atom in question as well as the number of available valence electrons.

\subsubsection{Orbitals and bonds}

The electrons in an atom are in reality not distributed as evenly as in figure 2.1a. Instead, they are expressed as an electron cloud surrounding the nucleus (figure 2.1b). Quantum mechanics govern the location of electronic charges inside the atom, thereby dictating where an electron is residing. Each electron state is described by a different wave function, $\Psi$, being either positive or negative. Only wave functions that are solutions to the Schrödinger equation are allowed. The square of the wave function, $\Psi^{2}$, describes the probability of finding an electron at a certain place at a certain time. The wave function solutions are called atomic orbitals and are described by quantum numbers, which determine the energy and shape of the orbitals. It is assumed that the electrons will be in the defined orbitals with $95 \%$ probability.
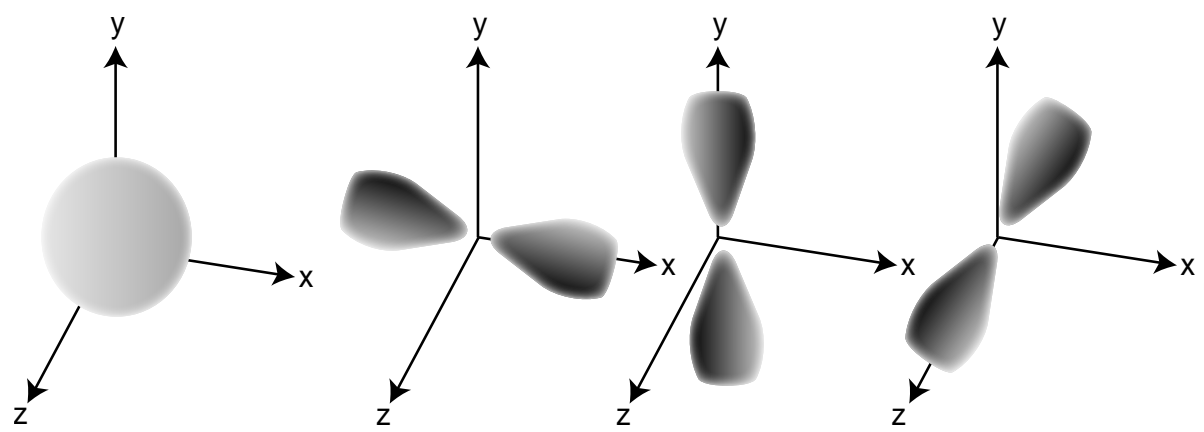

Figure 2.2 Atomic orbitals. Illustration of an $s$ orbital (left) and $p_{x}, p_{y}$ and $p_{z}$ orbitals (right).

In organic electronics, the $\mathrm{s}$ and $\mathrm{p}$ orbitals are of particular importance (figure 2.2). In carbon, the K-shell consists of one orbital, $1 \mathrm{~s}$, with the lowest energy. In the L-shell one $2 s$ orbital and three $2 p$ orbitals (in the $x$-, $y$ - and z-planes respectively) are found. The $2 s$ orbital is lower in energy than the $2 p$ orbitals (figure 2.3). One orbital can contain two electrons with different spin (up or down). The orbitals with the lowest energy are filled first. The electron configuration of carbon in its ground state is $1 s^{2} 2 s^{2} 2 p_{x}{ }^{1} 2 p_{y}{ }^{1}$. 


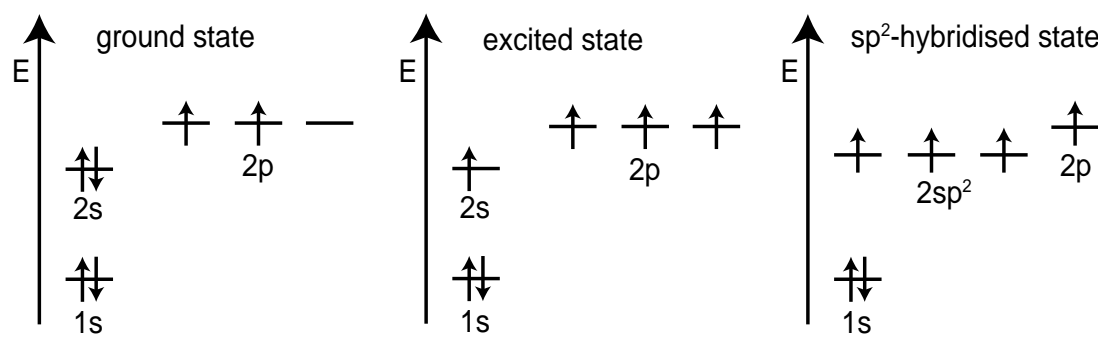

Figure 2.3 Electron configuration of carbon in its ground state (left), its excited state (middle) and after $\mathrm{sp}^{2}$ hybridisation (right).

Covalent bonds are formed between atoms when unpaired valence electrons are shared, thus creating filled outer electron shells in the participating atoms. In each bond two electrons, one from each atom, are shared. The bonds in a compound determine its physical and chemical characteristics to a great extent. As an example, diamond and graphite can be mentioned. Both materials are entirely composed of lattices of carbon atoms joined by covalent bonds. Diamond is known as a very hard material, it is electronically insulating and possesses a high thermal conductivity. On the other hand, graphite is brittle, electronically conducting and has a very low thermal conductivity. The differences between these two compounds are entirely due to differences in bond angles and lengths.

When atoms approach each other the atomic orbitals start to interact and overlap, finally forming molecular orbitals (figure 2.4). Molecular orbitals are linear combinations of atomic orbitals. As the atomic orbitals are either positive or negative, the interactions can be either constructive $\left(\Psi_{+}\right)$or destructive $\left(\Psi_{-}\right)$. In the case of constructive interactions, the electron density between the nuclei increases and the orbital is called bonding. In the other case when the electron density decreases the orbital is known as antibonding. When two atomic orbitals combine, one bonding and one antibonding molecular orbital are formed. The bonding orbital will possess a lower energy than the two individual atomic orbitals and will thus stabilize the two atoms. The antibonding orbital will instead have a relatively higher energy. Thus, the energy levels of the bond are separated and the larger the energy gap between them the stronger the bond. The electrons will fill the orbitals with lowest energy first, and if the total energy of the combined system is lower than that of the individual atoms a stable bond will be formed. Bonds (and bonding molecular orbitals) are either $\sigma$ (if circularly symmetrical along the bond axis), or $\pi$ (with a nodal plane passing through the bonded nuclei). The corresponding antibonds (and antibonding molecular orbitals) are denoted $\sigma^{*}$ and $\pi^{*}$. 


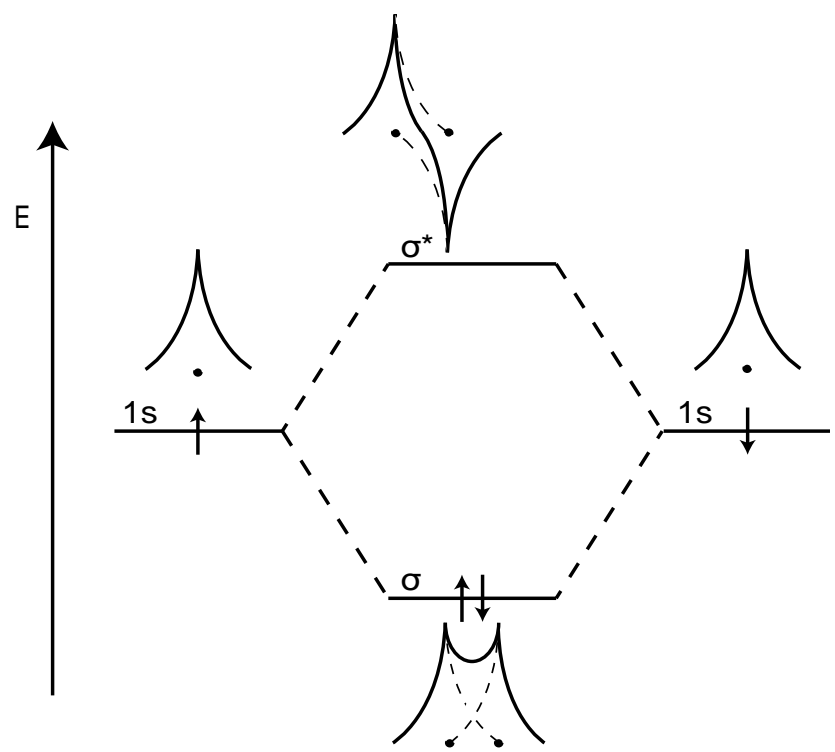

Figure 2.4 Overlap of two atomic 1s orbitals forming two molecular orbitals, one bonding $(\sigma)$ and one antibonding $\left(\sigma^{\star}\right)$ with different energy levels.

From a structural point of view, the simplest organic compound is methane, $\mathrm{CH}_{4}$. The carbon atom forms four bonds to the four hydrogen atoms, however a carbon atom only has two unpaired valence electrons (figure 2.3). The solution to this seemingly contradictory problem is that when carbon forms covalent bonds one electron is promoted from the $2 s$ orbital to the $2 \mathrm{p}_{z}$ orbital, creating an excited carbon atom with the electron configuration $1 s^{2} 2 s^{2} 2 \mathrm{p}_{\mathrm{x}}{ }^{1} 2 \mathrm{p}_{\mathrm{y}}{ }^{1} 1 \mathrm{p}_{\mathrm{z}}{ }^{1}$ resulting in four unpaired electrons (figure 2.3). Through a process called hybridisation the $2 s$ and $2 \mathrm{p}$ orbitals will combine. In $\mathrm{sp}^{3}$ hybridisation four $\mathrm{sp}^{3}$ hybrid orbitals with the same energy, arranged in a tetrahedral fashion with angles of $109.5^{\circ}$ between them, are formed. Four $\sigma$ bonds equivalent in length and strength are formed between the carbon and hydrogen atoms, each involving one $\mathrm{sp}^{3}$ orbital from carbon and one $1 \mathrm{~s}$ orbital from hydrogen. $\sigma$ bonds can also be formed between two $\mathrm{sp}^{3}$ orbitals on different carbon atoms. In all carbon compounds with only single bonds, including diamond, $\mathrm{sp}^{3}$ hybridisation exists, resulting in strong stable bond configurations.

In compounds such as ethylene, $\mathrm{C}_{2} \mathrm{H}_{4}$, a double bond links the two carbon atoms. A double bond consists of one $\sigma$ and one $\pi$ bond (figure 2.5). In this case, the $2 \mathrm{~s}$ and two of the $2 \mathrm{p}$ orbitals have hybridised into three $\mathrm{sp}^{2}$ orbitals with one $2 \mathrm{p}$ orbital remaining unchanged (figure 2.3). The $\mathrm{sp}^{2}$ orbitals arrange themselves in one plane with $120^{\circ}$ between them and form $\sigma$ bonds to either sorbitals on 
hydrogen or another $\mathrm{sp}^{2}$ orbital. The $\mathrm{p}$ orbital is perpendicular to the $\sigma$ bonds and will form a $\pi$ bond with another p orbital. $\pi$ bonds are generally weaker than $\sigma$ bonds as $\pi$ orbitals are higher in energy than $\sigma$ orbitals. Groups connected by single bonds can generally rotate freely, whereas double bonds instead tend to break when rotated. In graphite, the presence of $\pi$ bonds is responsible for giving the material different properties than diamond. Finally, carbon can also form triple bonds, where sp hybridisation results in two sp orbitals forming $\sigma$ bonds and two p orbitals forming two $\pi$ bonds.
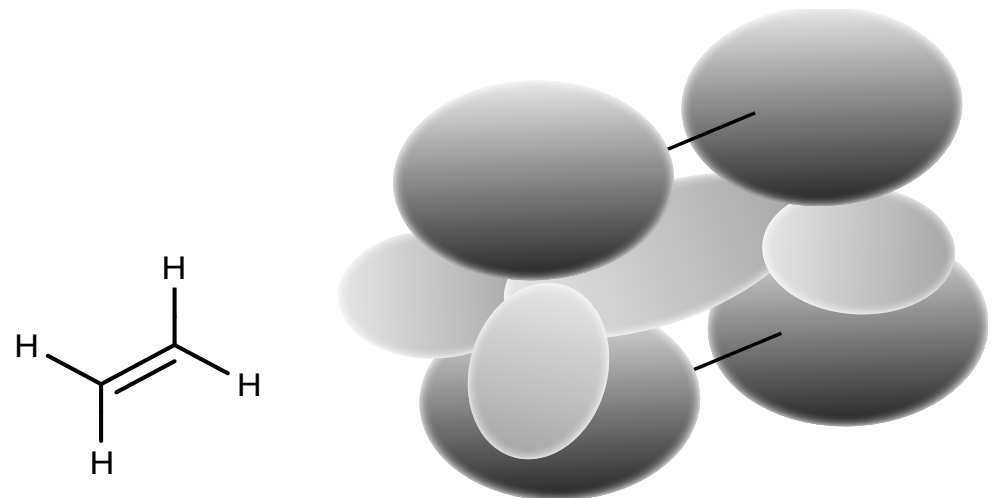

Figure 2.5 Ethylene molecule with $\sigma$ bonds (light grey) and $\pi$ bonds (dark grey).

\subsubsection{Origin of conductivity}

From a structural point of view, trans-polyacetylene (figure 2.6) is the simplest conjugated polymer. In this material all carbon atoms are $\mathrm{sp}^{2}$ hybridised. The $\pi$ bonds will give the molecule structure and rigidity, as they prevent rotation. The $2 \mathrm{p}_{z}$ orbitals are located perpendicular to the plane of the molecule and will start to overlap. Electrons in these orbitals are delocalized and will be able to move along the polymer chain. All the bonding $\sigma$ orbitals will be filled and the antibonding $\sigma^{*}$ orbitals will be empty.

The bonding and antibonding $\pi$ orbitals lie between the $\sigma$ orbitals in energy. The energy separating the highest occupied molecular orbital (HOMO) and the lowest unoccupied molecular orbital (LUMO) is called the band gap, $\mathrm{E}_{\mathrm{g}}$. For organic molecules with only $\mathrm{sp}^{3}$ hybridisation, such as diamond, the band gap will correspond to the large difference between $\sigma$ and $\sigma^{*}, 5.5 \mathrm{eV}$ in the case of diamond. ${ }^{[13]}$ This explains the insulating properties of these materials. In contrast metals has no band gap and hence posses a very high electronic conductivity. 


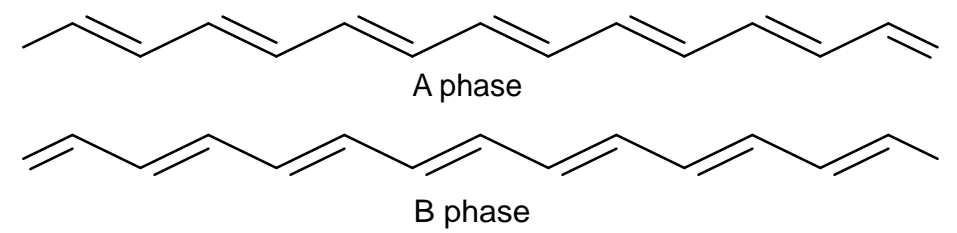

Figure 2.6 Trans-polyacetylene in two phases with different bond length alternations.

In molecules with $\mathrm{sp}^{2}$ hybridisation, $\pi$ and $\pi^{*}$ orbitals will constitute the HOMO and LUMO levels respectively. The number of $\pi$ and $\pi^{*}$ orbitals will increase with the number of carbon atoms and there will be a splitting of energy levels when the number of carbon atoms is doubled (figure 2.7). When the number of carbon atoms increases, the differences between consecutive energy levels will $\begin{array}{llll}\mathrm{CH}_{3} & \mathrm{C}_{2} \mathrm{H}_{4} & \mathrm{C}_{4} \mathrm{H}_{6} & \mathrm{C}_{2 \mathrm{n}} \mathrm{H}_{2 \mathrm{n}+2}\end{array}$

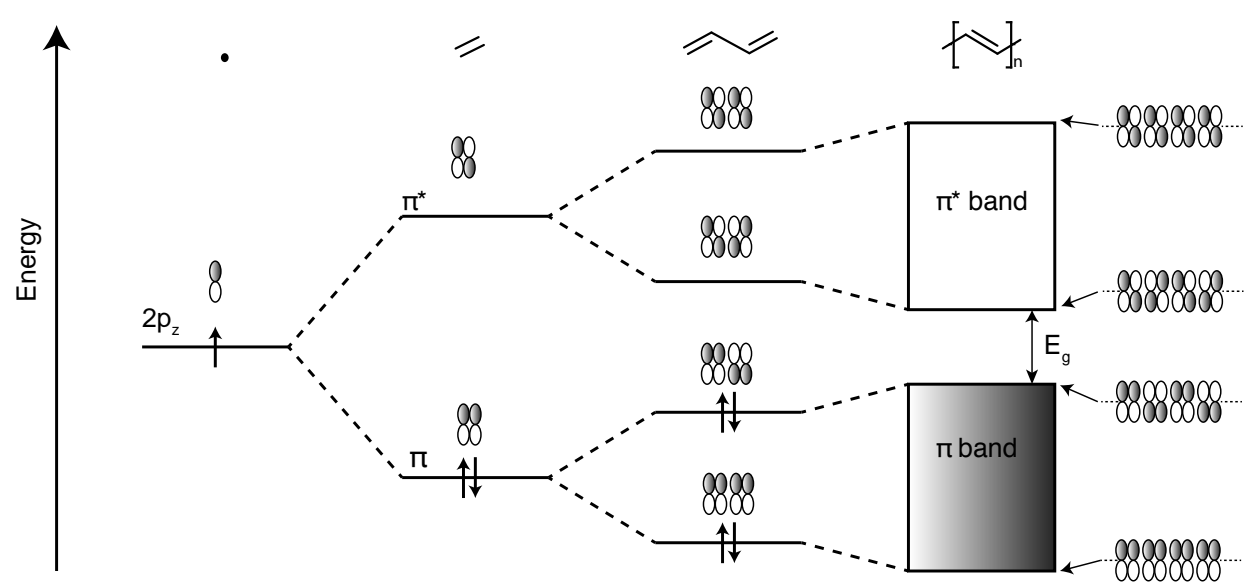

Figure 2.7 Splitting of energy levels when doubling the number of carbon atoms. At an infinite number of carbon atoms, energy bands are formed generating a band gap. Bonding and antibonding orbitals are denoted in different colours.

become successively smaller and eventually continuous energy bands will be formed (like in trans-polyacetylene). If all bonds in trans-polyacetylene were of the same length, the HOMO and LUMO would coincide and create a half-filled band making the polymer a quasi-metal. However, according to Peirls' theorem this configuration is unstable and instead the bond lengths will alternate between relatively shorter double bonds and longer single bonds, the lengths being $1.36 \AA$ and $1.44 \AA$ respectively. ${ }^{[14]}$ This will generate a band gap and thus the polymer will become a semiconductor. Typical $\mathrm{E}_{\mathrm{g}}$ values are $1.5-3 \mathrm{eV} \cdot{ }^{[15]}$ The empty $\pi^{*}$ band is often called the conduction band and the filled $\pi$ band is called the valence band. 


\subsection{Charge carriers and charge transport}

Within a polymer film, charges must be transported both along the conjugated chains and from chain to chain in order to obtain bulk conductivity. The two processes are rather different, both when it comes to the mechanisms involved and the speed of charge transfer. Charge carriers are created by either donation or acceptance of charges to the polymer chain, resulting in local molecular distortions creating charged quasi-particles (solitons or polarons).

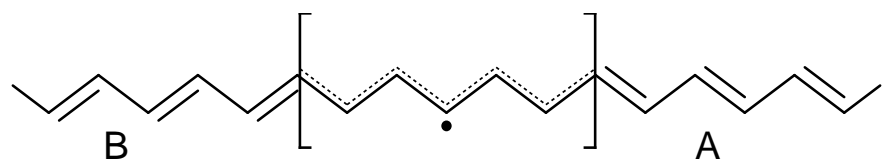

neutral soliton
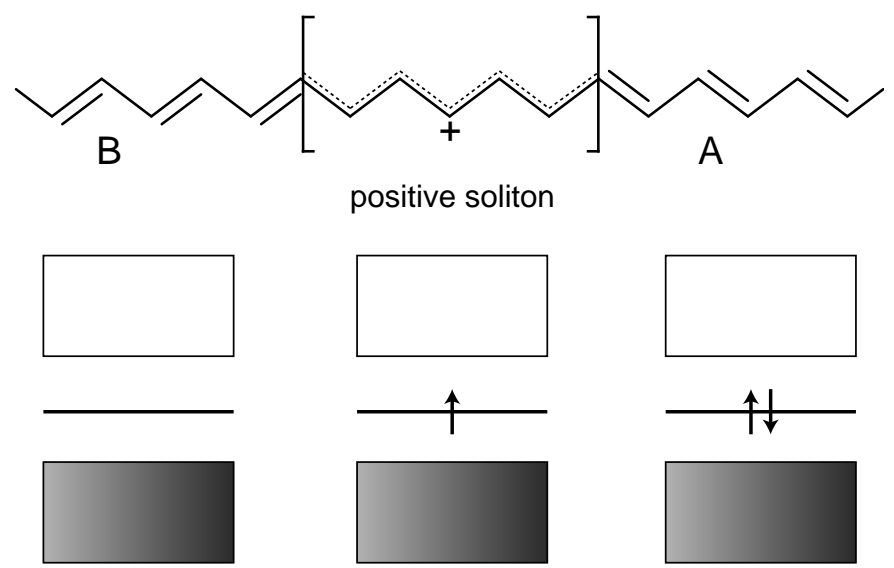

positive

soliton

neutral

soliton

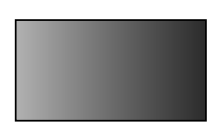

negative

soliton

Figure 2.8 Schematic illustrations of neutral and positive solitons in trans-polyacetylene (top) and band diagrams of neutral, positive and negative solitons (bottom).

\subsubsection{Solitons}

In trans-polyacetylene, two phases with different arrangements of the alternating single and double bonds are possible (figure 2.6). However, the bond length alternations are equal and the two phases therefore have the same energy, making them degenerate. A distortion within the molecule creates a soliton that extends over a few units in the boundary between the two phases. Within the soliton, all bond lengths are equal. The presence of a soliton will create an energy level in the middle of the band gap (figure 2.8). A soliton can be positive, neutral (with one unpaired electron) or negative (with two paired electrons). 


\subsubsection{Polarons and bipolarons}

Most conjugated polymers are non-degenerate and therefore solitons cannot be formed. When introducing charges to polythiophene, the polymer will locally change from its most stable aromatic form to the quinoid form (figure 2.9). The structural change will result in a higher energy but a lower ionization potential, facilitating incorporation of additional charges. The result is called a polaron, and this quasi-particle is delocalized over a few units along the polymer chain. A polaron will generate two new levels within the band gap (figure 2.10) and may, like a soliton, be positive, neutral or negative in charge. In some cases, two polarons can combine to form a bipolaron that will extend over a longer part of the polymer chain than a single polaron. Bipolarons will contain two charges that to some extent will repel each other, however it is energetically favourable to have the geometrical distortion closely localised on the same chain instead of distributed along two chains.

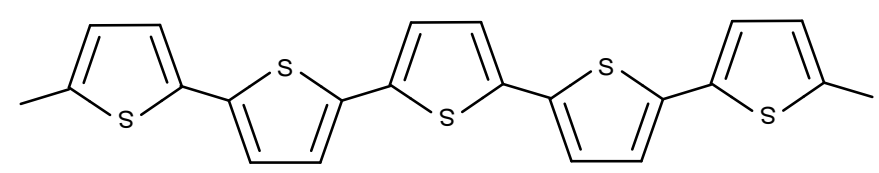

aromatic

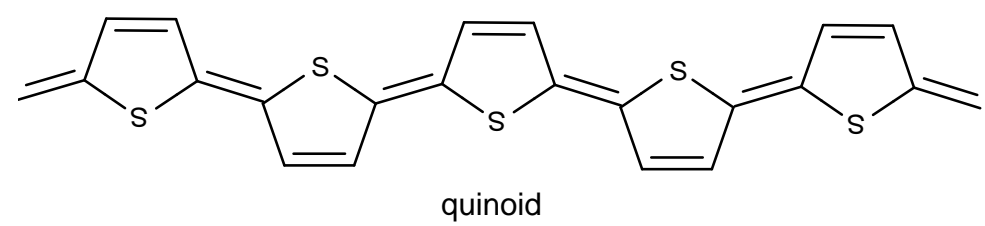

Figure 2.9 The aromatic and quinoid forms of polythiophene.

\subsubsection{Charge transport}

Solitons, polarons and bipolarons carry charge along the conjugated polymer chains and move freely due to the $\pi$ orbital overlap within the molecule. However, in a polymer film charges will also have to be transported from one chain to another. In a perfectly crystalline material neighbouring polymer chains will stack together with a high $\pi-\pi$ orbital overlap. In reality this is rarely the case in conjugated polymer films. Instead, the films are often highly amorphous, and molecules are associated mainly through weak van der Waal bonds, making the transport of charges from one chain to another the prime rate-limiting step in the overall charge transport. 


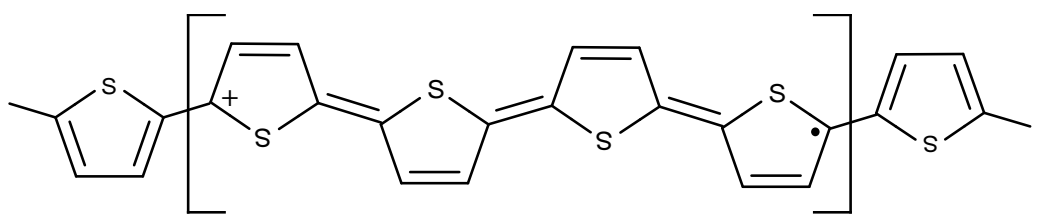

positive polaron

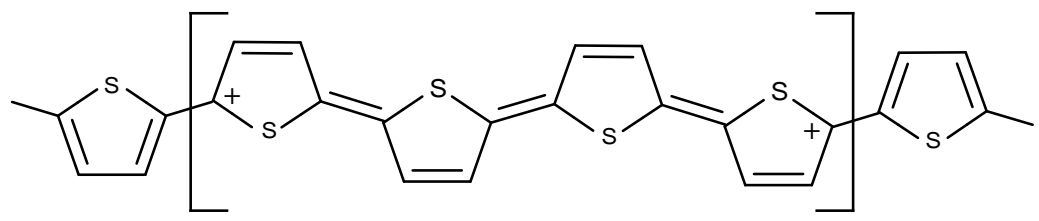

positive bipolaron

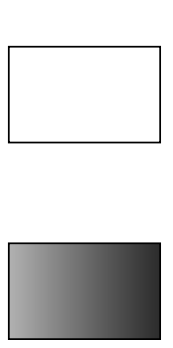

neutral
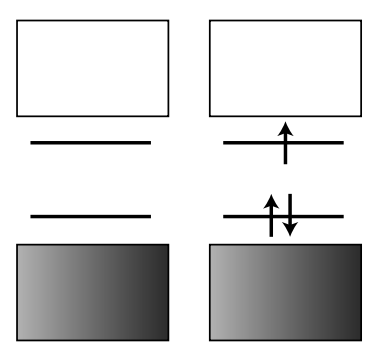

positive polaron

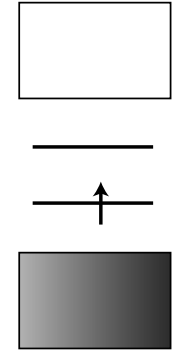

positive bipolaron

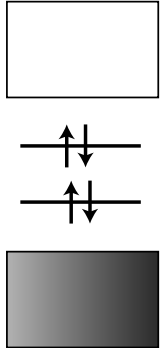

negative bipolaron

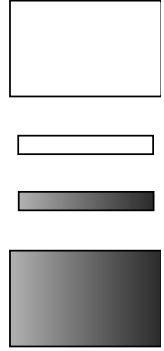

bipolaron bands

Figure 2.10 Schematic illustrations of a positive polaron and a positive bipolaron (top) and band diagrams of polarons and bipolarons (bottom).

The electrical conductivity of a conjugated polymer film will depend highly on the mobility within the material. The mobility $(\mu)$ of a charge is defined as the average migration speed within an applied electric field. The mobility is influenced by a number of factors including molecular packing, disorder, impurities within the film, molecular weight and also the density of charge carriers. For highly ordered conjugated polymer films, the mobility can be high, resulting in a good conductivity whereas the opposite is true for amorphous films. Impurities and defects in the film will generate trapping and localization of charges, thus decreasing the mobility. Typical values for the mobility are $10^{-6}-10^{-3} \mathrm{~cm}^{2} \mathrm{~s}^{-1} \mathrm{~V}^{-1},{ }^{[16]}$ but by increasing the order of the film it can be greatly improved to values reaching $0.6 \mathrm{~cm}^{2} \mathrm{~s}^{-1} \mathrm{~V}^{-1}$ and above. ${ }^{[17,18]}$ It is also possible to have regions within the same film with different structural order, having high mobility in certain domains surrounded by larger amorphous areas with relatively lower mobility. ${ }^{[19]}$ In that case, the charge transport between different regions will then be the limiting factor for transport. Recent work suggests that in certain polymers, typically with high 
molecular weight, the ordered regions can form networks through the long conjugated chains, increasing the mobility even though the film is largely amorphous. ${ }^{[20,21]}$

Understanding the charge transport in conjugated polymers is complex. In a crystalline material, electrons and holes are delocalized in the conduction and valence bands and can move freely. However, in a disordered material new energy levels will appear in the band gap creating localized states that will serve as traps for charges, thus making them immobile until they are released. ${ }^{[22]}$ There are a number of different models describing the charge transport within conjugated polymers. Assuming that charges are localized to single states and that electron-phonon coupling is weak, Miller and Abrahams proposed a model based on charges hopping between states. ${ }^{[23]}$ Mott later suggested a variable range hopping (VRH) model, suitable for transport in highly disordered systems with localized states. The Bässler's Gaussian disorder model (GDR) is commonly applied to treat the charge transport in conjugated polymer films. Bässler here assumed a Gaussian distribution of states and hopping distances together with a temperature dependence that was larger than in the VRH model. ${ }^{[24]}$

\subsection{Doping}

In their intrinsic state, conjugated polymers generally have conductivities in the range from $10^{-10} \mathrm{~S} \mathrm{~cm}^{-1}$ to $10^{-5} \mathrm{~S} \mathrm{~cm}^{-1}$, making them appear as electronic insulators. ${ }^{[2]}$ However, when compared to typical insulators, their ionization potential (electron affinity) is much lower (higher) due to the conjugated $\pi$ system, facilitating introduction of charges into the polymer. By the process of doping, the conductivity of a conjugated polymer can be increased several orders of magnitude to reach metallic values from $10^{3}$ to $10^{5} \mathrm{~S} \mathrm{~cm}^{-1}$ and even higher. ${ }^{[2]}$ Highly doped materials are sometimes referred to as synthetic metals or conducting polymers.

Doping, as a method to reach high electronic conductivity, was first presented for polyacetylene. The conductivity was increased by several orders of magnitude through a redox process. ${ }^{[3,25]}$ Introduction of negative charges is referred to as $\mathrm{n}$-doping, and the removal of charges as $\mathrm{p}$-doping. In redox doping, this corresponds to reduction and oxidation respectively, and can be either chemically or electrochemically induced. Doping will change not only the electronic properties of the material, but also the optical, magnetic and structural properties. 
In electrochemical doping, electrons are removed to or added from an electrode in direct contact with the polymer and the applied potential will control the doping level. As charges are created within the polymer during doping, counter ions of opposite charge are needed to maintain electroneutrality within the film. In the case of p-doping (electrochemical oxidation), anions from the electrolyte will be incorporated into the polymer film. In chemical doping, electrons are transferred to electron accepting molecules or from electron donating molecules. Commonly used dopants are $\mathrm{FeCl}_{3}$ and $\mathrm{AsF}_{5}$. Both electrochemical and chemical doping are dependent on the oxidation potential of the polymer, in turn decreasing with increasing polymer chain length. ${ }^{[26]}$ The degree of doping will impact the conductivity of the polymer film, at high doping levels bipolaron bands are assumedly formed. ${ }^{[22]}$ The conductivity is also affected by the type of dopant and counter ion used. ${ }^{[27]}$ For many conjugated polymers the optimal doping level is around 0.3 , meaning that approximately every third monomer unit is charged. ${ }^{[22]}$ When increasing the doping level even further, Coulombic repulsion occurs and finally the polymer will be degraded through a process known as overoxidation. ${ }^{[28]}$

There are also other types of doping. Examples include photo-doping, charge injection-doping and doping through the addition of acids.

\subsection{Electrochromism}

A molecule can absorb photons of energy corresponding to the difference between the molecule's ground state and excited state. Once in the excited state, the molecule can return to the ground state by radiative or non-radiative processes. Radiative decay involves the emission of a photon while non-radiative decay instead transfers energy to surrounding molecules (heat). The emitted light will always be lower in energy (red-shifted) than the absorbed light due to vibrational losses.

In a neutral conjugated polymer, the difference between the ground state and excited state corresponds to the band gap. The small band gap (typically 1.5 $3 \mathrm{eV}$ ) corresponds to wavelengths within the visible spectrum. Upon doping, the resulting charge carriers will generate new levels within the band gap (figure 2.10), thus changing the energy needed for excitation. This means that a conjugated polymer will emit light of different colour depending on the degree of doping. Doping can be controlled by electrical means, giving that the light absorption characteristics can be modulated by electronic addressing. The phenomenon in which electrochemical switching changes the colour of a material, is called 
electrochromism. ${ }^{[29,30]}$ An example of electrochromism in conjugated polymers is shown in figure 2.11 where poly(3,4-ethylenedioxythiophene) exhibits different absorption characteristics depending on its redox state. In the neutral state the band gap is larger than in the doped (oxidised) state where polarons and bipolarons are present in the band gap and governs the optical absorption characteristics. By fine-tuning the structure of conjugated polymers by the addition of different side chains altering the band gap, light emission in different colours can be obtained. Electrochromic applications include for example displays ${ }^{[30,31]}$ and smart windows. ${ }^{[32]}$

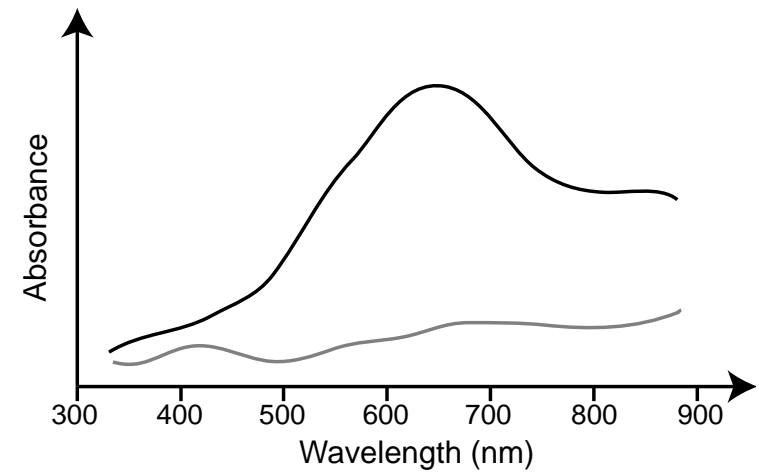

Figure 2.11 Sketch of the absorption spectra of neutral (black) and oxidised (grey) poly(3,4-ethylenedioxythiophene).

\subsection{Different conjugated polymers}

One of the first conjugated polymer to be presented was polyacetylene. It can be doped to reach high conductivities but suffer from other drawbacks, such as difficulties in processing and instability in air. Today, a vast range of tailor-made polymers, each with a unique set of properties suited for a specific application, exists. Polyaniline is another frequently used conjugated polymer with good processability that can be doped by the addition of an acid. However, polyaniline is potentially toxic when degraded. Polythiophene and its derivatives have been extensively used over the last years, examples include poly(3-hexylthiophene), P3HT, which is often employed when making organic thin film transistors. For conjugated polymers to be used in organic bioelectronics applications, it is important that the polymer is stable, biocompatible and that it easily can be to modified to suit different biological requirements and demands. Polypyrrole and 
poly(3,4-ethylenedioxythiophene), PEDOT, (figure 2.12a,b), are materials commonly explored in bioelectronics applications.

\subsubsection{Polypyrrole}

Polypyrrole was first synthesized from the pyrrole monomer in the 1960s, but was not extensively studied nor explored in electronics applications. It was later "rediscovered" and has since then been extensively used in various organic electronic applications. In its p-doped state it appears black in colour and can reach conductivities of $40-200 \mathrm{~S} \mathrm{~cm}^{-1}{ }^{[27]}$ The $\mathrm{n}$-doped state of polypyrrole is highly unstable in air due high reactivity when exposed to oxygen. When polypyrrole is electrochemically switched between its oxidised and reduced state, the volume changes dramatically. ${ }^{[33]}$ This has been used to created polymer actuators for use as artificial muscles ${ }^{[34,35]}$ and in drug delivery applications. ${ }^{[36]}$ Other bioelectronics applications using polypyrrole include sensors, ${ }^{[37]}$ coating of neural probes ${ }^{[8]}$ and stimulation of cell growth. ${ }^{[9]}$

\subsubsection{PEDOT}

PEDOT was developed in the 1980's in order to create a water-processable derivative of polythiophene. ${ }^{[38]}$ It has a conductivity around $300 \mathrm{~S} \mathrm{~cm}^{-1}$ and is very stable in its oxidised, p-doped, state. ${ }^{[39]}$ The neutral state is in contrast highly unstable due to its low oxidation potential. PEDOT is transparent and light blue in its oxidised state and is dark blue in its neutral state. ${ }^{[40]}$

In order to make processing in aqueous media possible, poly(styrene sulphonate), PSS, is used as the counter ion. The resulting emulsion of PEDOT:PSS, originally developed as an antistatic coating by Agfa, is water soluble and results in thin films with a conductivity of $10 \mathrm{~S} \mathrm{~cm}^{-1}$ and excellent stability. ${ }^{[39]}$ The conductivity can be increased further by secondary doping using for example diethylene glycol. ${ }^{[41]}$

Due to its biocompatibility ${ }^{[42]}$ and excellent stability when compared to polypyrrole, ${ }^{[43]}$ PEDOT, synthesised using different methods and with different counter ions, has been increasingly used within bioelectronics applications. Examples of such applications include drug delivery, ${ }^{[7]}$ sensors, ${ }^{[4]}$ interactions with cells ${ }^{[45,46]}$ and as the active material in ionic transport devices (iontronics). ${ }^{[4]}$ 

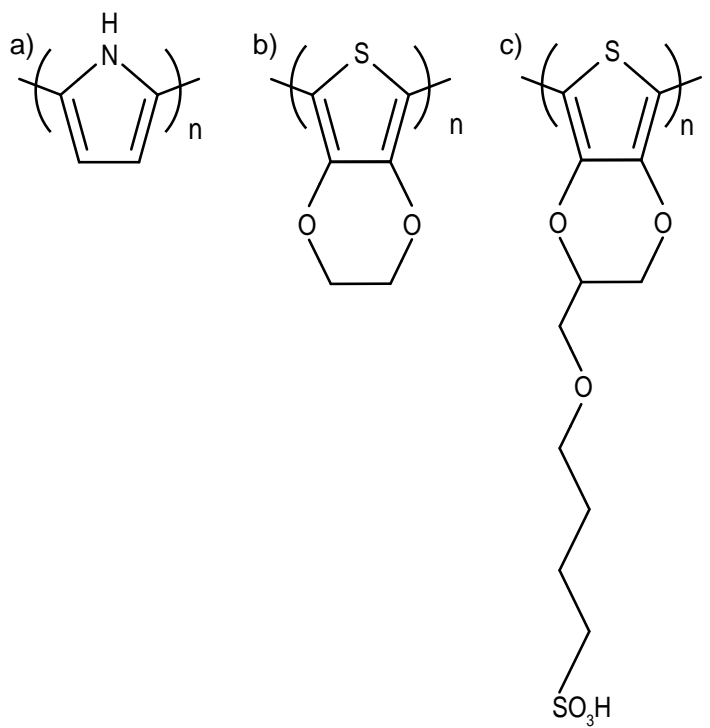

Figure 2.12 Examples of conjugated polymers: polypyrrole (a), PEDOT (b) and PEDOTS.H (c)

\subsubsection{PEDOT-S}

Even though the use of PSS as the counter ion enabled aqueous processability of PEDOT, the resulting material system is a dispersion and not a truly water-soluble polymer. To avoid processing in organic solvents and to facilitate interactions with biomolecules, water-soluble conjugated polymers are attractive. One way to realize such a polymer is to introduce charged/polar side chains on the monomer, ${ }^{[48]}$ resulting in a polymer with charged/polar side chains along the conjugated backbone. The polymer will also be self-doped, ${ }^{[49]}$ meaning that the counter ions needed during doping will be present on the polymer itself.

Water-soluble PEDOT has been synthesized by adding an alkoxysulphonate functionality to the EDOT monomer, ${ }^{[50,51]}$ resulting in the derivative poly(4-(2,3dihydro-thieno[3,4-b][1,4] dioxin-2-ylmethoxy)-butane-1-sulfonic acid, commonly referred to as PEDOT-S (figure 2.12c). It is fully water-soluble, self-doped and has a conductivity of $30 \mathrm{~S} \mathrm{~cm}^{-1}$. ${ }^{52]}$ PEDOT-S is usually prepared to yield a sodium salt, but during synthesis $\mathrm{Na}^{+}$can be exchanged for $\mathrm{H}^{+}$, creating PEDOT-S:H with somewhat different properties. 


\section{ELECTROCHEMISTRY}

Electrochemistry denotes the phenomenon when a spontaneous chemical reaction generates electricity and when an applied electrical potential induces a nonspontaneous change in a compound. The central process is the transfer of electrons from one electrode to another through external wiring at the same time as an ionic current flows in the opposite direction through an electrolyte. Conjugated polymers, typically display different properties in their oxidised, neutral and reduced states, making electrochemical techniques important when studying these polymers.

\subsection{Oxidation and reduction}

Oxidation is the removal of an electron from a molecule, creating a positively charged molecule. Reduction is the opposite process, the addition of an electron creating a negatively charged molecule. The two processes are normally coupled so that one species is oxidised and another one is reduced in a so-called redox reaction. An electrochemical reaction is often divided into two half reactions, one for oxidation and one for reduction (figure 3.1). At one electrode (the anode), oxidation occurs and electrons are transported to the other electrode (the cathode) where reduction occurs. At the same time, anions and cations move in opposite direction in the electrolyte, and possibly also through a salt bridge to create an ionic current. Traditionally, metal electrodes are used, on one electrode metal ions from the electrolyte will be reduced to deposit a metal layer on the electrode, and on the other the metal electrode itself will be consumed (oxidised) to create cations that enter the electrolyte. Alternatively, inert metal electrodes can be used to study reactions of electrochemical species present in the electrolyte.

Conjugated polymers are redox active, meaning that they can be oxidised and reduced back and forth between their doped $\left(\mathrm{P}^{+}\right.$or $\left.\mathrm{P}^{-}\right)$and neutral states $\left(\mathrm{P}^{0}\right)$ (equation 1 and 2).

$$
\begin{aligned}
& P^{0} ! \stackrel{q x}{\rightarrow} \rightarrow P^{+}+e^{-} ! \stackrel{\text { rod }}{\rightarrow} \rightarrow P^{0} \\
& P^{0}+e^{-} \stackrel{r e d}{\longrightarrow} P^{-} \stackrel{o x}{\longrightarrow} P^{0}+e^{-}
\end{aligned}
$$


Generally, one of the redox states is more stable than the other. ${ }^{[53]}$ For the polymers used in this thesis, the oxidised state is more stable and thus mainly pdoping and its associated electrochemistry will be discussed. Generally, reduction will refer to the process of reducing a p-doped polymer to its neutral state, not ndoping.

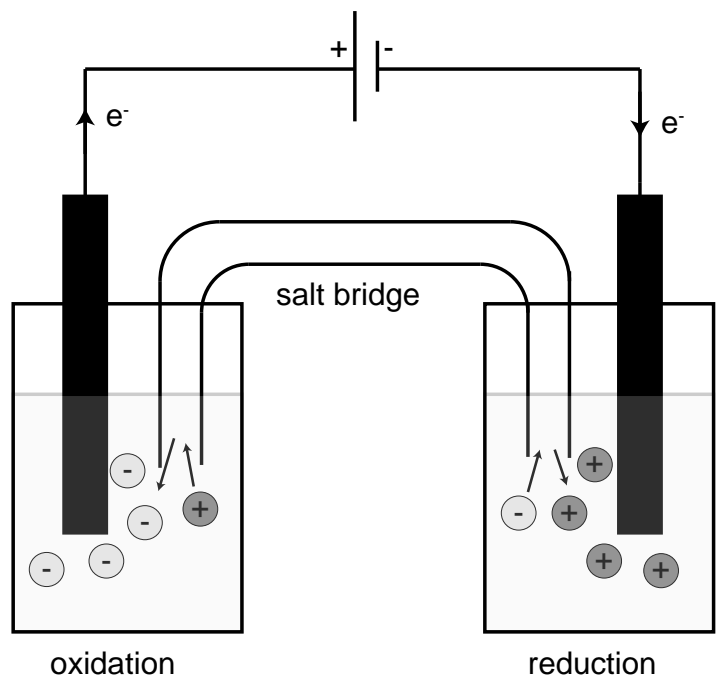

Figure 3.1 The electrochemical cell, showing two metal electrodes connected to a power source and the two half cells being connected through a salt bridge. Anions migrate to the positively biased electrode and cations to the negatively biased electrode.

As discussed in chapter 2, counter ions are needed during doping to maintain electroneutrality in the polymer film. In the case of p-doped polymer films, the polymer is partially oxidised during synthesis and anions are inserted for charge compensation. When a p-doped polymer is subsequently reduced to its neutral state, there will be additional negative charges within the film. If the anions are small or moderately sized ( $\mathrm{A}^{-}$in equation 3 ), they can be expelled from the film (equation 3).

$$
P^{+}: A^{-}+e^{-} \rightarrow P^{0}+A^{-}
$$

If instead a large anion, such as a polyanion, ( $\mathrm{M}^{-}$in equation 4) is used it will not be able to diffuse out of the film and instead cations $\left(\mathrm{C}^{+}\right)$from the electrolyte will enter the film ${ }^{[54]}$ (equation 4). For medium sized counter ions, it is possible that both mechanisms occur simultaneously or at different stages during redox cycling. ${ }^{[33]}$

$$
P^{+}: M^{-}+e^{-} \rightarrow P^{0}: M^{-}: C^{+}
$$


When switching a polymer film between the oxidised and neutral states, ions will diffuse in and out of the film depending on the redox state and type of counter ion. In a typical electrochemical experiment with conjugated polymers, polymer films constitute one or both of the involved electrodes. For conjugated polymers, the electrochemical reactions thus occur inside the electrode and not in the electrolyte. Ions are transported through the electrolyte and then in and out of the polymer electrodes. A simple electrochemical device involving two PEDOT:PSS electrodes is shown in figure 3.2. As PSS is a polyanion, the charge compensation mechanism upon reduction is the inclusion of small cations from the electrolyte.

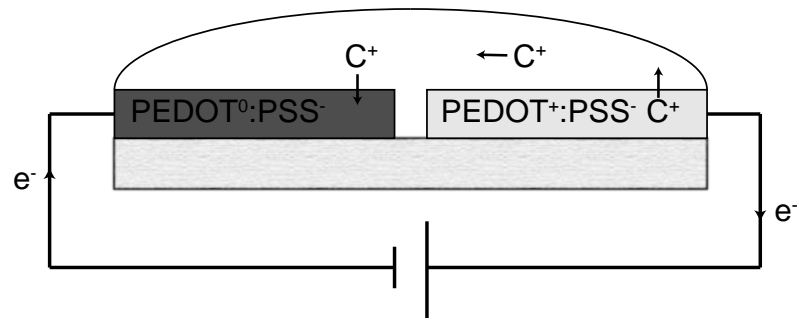

Figure 3.2 Simple electrochemical device with two PEDOT:PSS electrodes on a carrier substrate, one reduced (dark) and one oxidised (light). Cations $\left(\mathrm{C}^{+}\right)$will diffuse into the reduced electrode and out of the oxidised one, creating an ionic current.

\subsection{Electrolytes}

An electrolyte is a species that can form ions when immersed in a solution and thus conduct electricity. An example of a typical electrolyte is sodium chloride, $\mathrm{NaCl}$, in water. When dissolved in water $\mathrm{NaCl}$ will dissociate into $\mathrm{Na}^{+}$and $\mathrm{Cl}^{-}$ions, forming an aqueous electrolyte solution. In aqueous solutions, water molecules will surround the ion to form a hydrated ion. In electrochemistry, electrolytes are needed to provide a pathway for charge transport between the electrodes (figure $3.1)$.

\subsubsection{Different electrolytes}

Electrolytes can be based on either organic solvents or water. In addition, there are ionic liquids, that in reality are defined as liquid salts without a solvent. Electrolytes are not always prepared as liquid solutions, it is also possible to have gel and solid electrolytes. Salts can also be dissolved in a neutral polymer matrix, creating a polymer electrolyte. The choice of electrolyte depends on the application in question, in bioelectronics generally aqueous solutions are used as they are more 
biocompatible. However, organic solvents are typically more stable within a wider potential range.

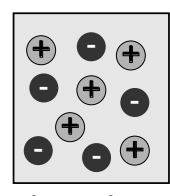

electrolyte solution

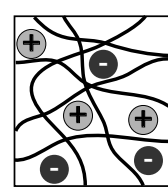

polymer electrolyte

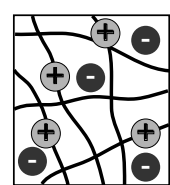

polycation

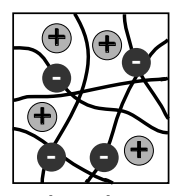

polyanion

polyelectrolytes

Figure 3.3 Different types of electrolytes.

Any solution containing charged species, can be used as an electrolyte in bioelectronics. This means that for example solutions containing molecules such as proteins and DNA, and even biological fluids (and tissues) are possible electrolyte candidates. The conductivity of an electrolyte will increase with the concentration of ions in the solution. The ionic species can be small and mobile, as $\mathrm{Na}^{+}$and $\mathrm{Cl}^{-}$ ions, but it can also be large molecules with charged groups such as PSS. These are referred to as polyelectrolytes. A polyelectrolyte with fixed negative charges is called a polyanion, and polyelectrolytes with fixed positive charges are referred to as polycations. Small cations and anions, referred to as counter ions, will be associated with the larger chains of polyanions and polycations respectively. In solution or in a heavily hydrated state, these counter ions will posses a higher mobility compared to the larger-sized polycations and polyanions. In the dry state, only the small ions are able to diffuse or migrate. Examples of different electrolytes are shown in figure 3.3 .

\subsubsection{Ion transport}

Ions are transported in an electrolyte mainly by two different processes, diffusion and migration. Diffusion arises due to differences in concentration throughout the electrolyte, whereas migration is transport that arises from an electric field. Both diffusion and migration characteristics will be affected by the type of electrolyte. Important parameters include the size of the hydrated ion and the viscosity of the solvent. In addition to diffusion and migration, fluid will be transported through the process of convection. Convection arises due to differences in for example temperature throughout the electrolyte.

In electrochemical reactions involving conjugated polymers, the electron transport through the polymer film is typically very fast due to the high conductivity of the doped polymer. Ion diffusion is a relatively much slower 
process, and as counter ions from the solution are often involved during electrochemical reactions to counteract additional charges within the polymer film, diffusion will typically be the rate-limiting step in many electrochemical reactions of conjugated polymers. ${ }^{[55]}$

\subsection{Conjugated polymer electrodes}

Often thin conjugated polymer films are used as electrodes in electrochemical devices and in various electrochemical set-ups. In electrochemical reactions, the electrodes are immersed in an electrolyte. In contact with an aqueous electrolyte, most conjugated polymers will swell due to water uptake of the film. ${ }^{[56]}$ In addition, small solvated ions in the electrolyte will be able to diffuse in and out of the film, regardless of any applied potential.

\subsubsection{Electric double layer}

When a metal electrode is placed in contact with an electrolyte, an electric double layer (EDL) will form due to an electric potential difference between the electrode and electrolyte. The EDL can be described by the Goüy-Chapman-Stern model as being composed of two parts: the Helmholtz layer and a diffuse layer (figure 3.4).

The Helmholtz layer closest to the electrode consists of a layer of solvent molecules and solvated ions of opposite charge to the electrode, adhered to the surface. The potential drop across this layer is steep and linear. The diffuse layer extends further into the bulk of the electrolyte and is composed of ions of both positive and negative charge. Closest to the electrode there will be an excess of ions with opposite charge compared to the charges along the electrode surface. The potential drop across the diffuse layer is exponential.

When applying a potential to a metal electrode in an electrolyte, an EDL will form. If there are no electrochemically active species, capacitive charging of the EDL will occur and as a steady state is reached, no additional current will flow in the system. On the other hand, if electrochemically active species are present, a small current will flow even after formation of the EDL, as electrochemical reactions take place at the electrode. Diffusion of the electrochemically active species to the electrode will often limit the rate of the reaction. 


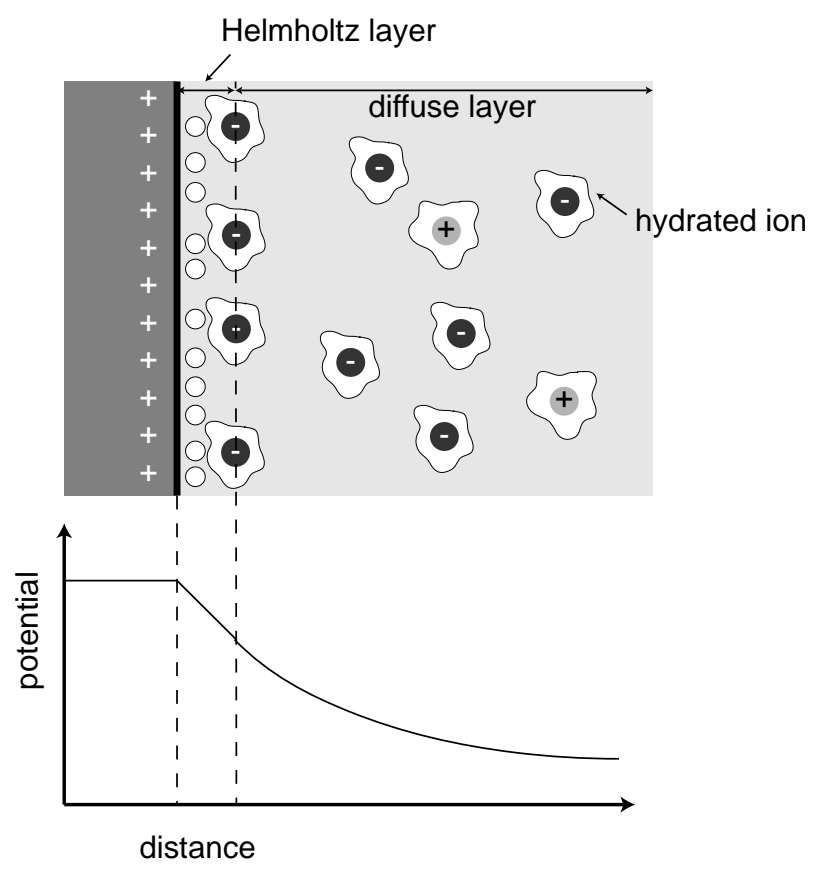

Figure 3.4 Electric double layer according to the Goüy-Chapman-Stern model, showing the Helmholtz layer and the diffuse layer. Hydrated anions and cations as well as water molecules (white circles) are included.

\subsubsection{Redox cycling}

When using conjugated polymers, the electrodes themselves will be electrochemically active. As counter ions from the solution are needed the electrodes will be partly solvated and the solvent will influence the electrochemical reactions. ${ }^{[55]}$ Starting with a fully p-doped conjugated polymer, a redox cycle will be discussed below. Redox cycling is often performed using cyclic voltammetry, described further in section 5.2.3. When reducing a p-doped (oxidised) polymer, the number of positive charges within the polymer decreases. To maintain electroneutrality, either anions are be expelled or cations are inserted. When switching the potential and re-oxidising the polymer, the number of positive charges increases again and the reverse transport of ion will occur. ${ }^{[57]}$ Then, the process is repeated, initiating a redox cycling process. The occurrence of cation insertion or anion expulsion during reduction, will depend on a number of factors including the size of the counter ion, ${ }^{[54]}$ the rate of the cycling ${ }^{[33]}$ and the ions present in the electrolyte. ${ }^{[34]}$ Both diffusion and migration is important in order to transport ions to the electrode surface for fast redox cycling. ${ }^{[56]}$ 


\subsubsection{Ion exchange properties}

An ion exchange membrane is composed of a cross-linked polyelectrolyte. When put in solution, the membrane will take up solvent and exchange mobile ions. Counter ions have opposite charge with respect to the membrane whereas co-ions have the same charge. At low enough electrolyte concentrations, only counter ions will be able to enter the membrane, as co-ions are repelled by the fixed charges within the membrane.

Conjugated polymers with fixed charges, like PEDOT-S, will in reality behave as a polyelectrolyte. A thin film of PEDOT-S has fixed negative charges, some that will be bound to the partly oxidized polymer backbone. The additional charged groups will initially be associated to $\mathrm{Na}^{+}$, but upon submersion in an electrolyte the $\mathrm{Na}^{+}$will be exchanged with mobile cations in the electrolyte.

\subsection{Electrochemically induced changes}

When electrochemically reducing a conjugated polymer film from its oxidised to its neutral state or vice versa a number of changes occur within the film. In the oxidised state the polymer is p-doped and contains polarons and/or bipolarons as the electronic charge carriers. Consequently, the electronic conductivity is high. Upon reduction, the number of charge carriers decrease along with the conductivity. In the fully neutral state, the polymer typically exhibits a very low conductivity. Electrochromism is another example of an electrochemically-induced change of the polymer properties. The most important electrochemically-induced changes used in this thesis are changes in surface energy and composition, and also volume of the conjugated polymer. They will be discussed further below.

\subsubsection{Surface energy and composition}

Molecules at the surface of a solid or liquid behave differently than the molecules within the bulk, as they lack neighbours in one direction. It is energetically more favourable to decrease the surface area as much as possible. The surface energy, $\gamma$, is determined by how much energy that is needed to increase the surface area and is characteristic for a solid or liquid at the interface with a gas. A high surface energy will generally mean that the solid in question is hydrophilic and a low surface energy then means that it is hydrophobic. Many conjugated polymers can switch between more or less hydrophilic states when changing the redox state. ${ }^{[58-60]}$ Generally, the doped state is the most hydrophilic one. Hydrophilicity will also be 
influenced by the choice of counter $\operatorname{ion}^{[61]}$ and also by the roughness of the polymer film. ${ }^{[62]}$
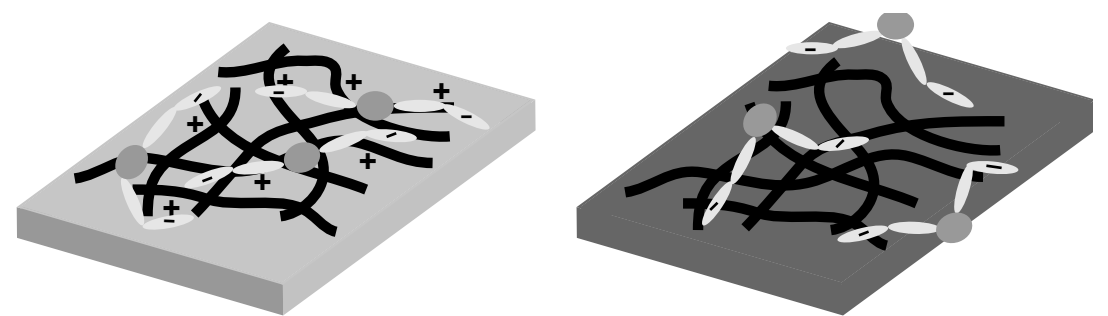

Figure 3.5 Changes in interactions between large counter ions and oxidised (left) and reduced (right) polymer chains.

When using large counter ions that will remain within the film regardless of redox state, they will remain in the film but they will be less tightly bound to the polymer backbone in the neutral state. As they are no longer strongly associated with the polymer chain, they can expose different groups at the surface of the film (figure 3.5). This can be used to guide interactions with other molecules and also with growing cells. Changes in surface composition depending on redox state has been shown for PANI doped with DBS, ${ }^{[58]}$ and also for both polypyrrole ${ }^{[63]}$ and PEDOT doped with heparin. ${ }^{[45]}$

\subsubsection{Volume}

Another electrochemically-induced change, that for some polymers can be quite dramatic, is the volume change. Volume changes during redox cycling have been studied extensively for polypyrrole ${ }^{[33,34,54]}$ and to a lesser extent for PEDOT. ${ }^{[64,65]}$ The expansion is associated with the insertion of ions and solvent for charge compensation during doping and de-doping of the polymer (figure 3.6). When using a large immobile anion in a p-doped polymer, expansion will occur when reducing the polymer as cations from the electrolyte are needed for charge compensation. Upon re-oxidation, the polymer will instead contract.

Besides the actual inflow of ions and solvent due to charge compensation of the redox reaction, there are other parameters that will impact the volume control of the film. Structural changes within the polymer might also be of importance, especially for PEDOT. ${ }^{[64]}$ The valence of the mobile ions is also important, with less expected volume expansion for di- or trivalent ions. ${ }^{[34]}$ In addition, both osmotic forces ${ }^{[6,67]}$ and migration of ions in the electric field ${ }^{[56]}$ has been suggested to influence the volume changes. 

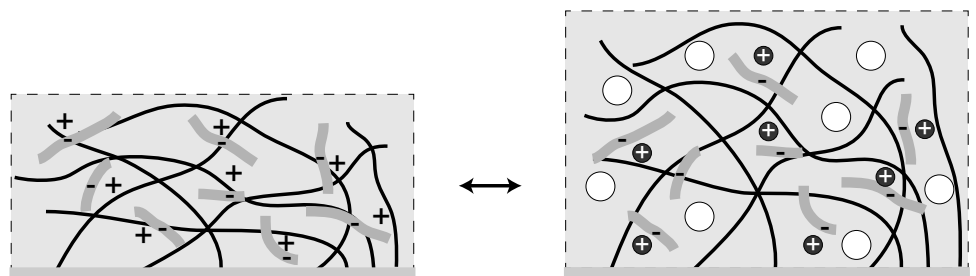

Figure 3.6 Volume changes in conjugated polymers upon oxidation (left) and reduction (right). Large immobile counter ions (grey) remain in the film upon reduction, and cations (black) and water (white) enter.

Electrochemical control of volume changes has been studied mainly for polypyrrole films. This material has been explored in various actuators to create for example artificial muscles. ${ }^{[35,68,69]}$ The electronic control over expansion and contraction resulting from the volume changes when switching the redox state has also been employed in drug delivery devices. ${ }^{[7,36,70]}$ 


\section{ORGANIC BIOELECTRONICS}

The aim in bioelectronics is to combine electronics with biological systems, such as cells and tissue. Bioelectronics applications can broadly be divided into two categories: sensing and stimulation. A common sensing application is the recording of electronic signals from biological systems. ${ }^{[71]}$ Another is the detection of certain biochemical compounds such as proteins in solution, often using a transistor to amplify the signal. ${ }^{[72]}$ Chemical specificity of the detection can be achieved by adding a biological recognition element, for example an antibody or an enzyme, to the sensor. ${ }^{[73]}$ Stimulation can occur either by direct electronic pulses to the biological system in question or by electronically triggered release of chemical substances that in turn are responsible for the actual stimulation.

Conjugated polymer materials are suitable for bioelectronics applications as they are generally soft, flexible and transparent. ${ }^{[27,74]}$ The suitability can be improved further by tailor-made synthesis and addition of biologically relevant functional groups. ${ }^{[63,75]}$ Another advantage of conjugated polymers is that the materials can be coated on a wide variety of substrates, including $3 \mathrm{D}$ scaffolds. ${ }^{[6,77]}$ In addition, it is important that materials that are to interact directly with cells and tissue are biocompatible; no potentially toxic substances like monomers or solvents from the synthesis can leak out of the polymer. Several biocompatibility studies have shown that conjugated polymers like PEDOT $^{[42,75]}$ and polypyrrole ${ }^{[36,78]}$ are suitable substrates for cell cultures as well as implants.

Over the last few years, the field of organic bioelectronics - using organic conjugated polymers for bioelectronics - has grown rapidly and today there are numerous examples of different applications. Organic electronic transistors have been used to sense brain activity in vivo, ${ }^{[79]}$ and electrodes coated with conjugated polymers have been used to record neural signals. ${ }^{[76,80]}$ Stimulation devices based on conjugated polymers have also been extensively explored. These are typically based either on an electroactive surface that directly stimulates cells or tissue through electronic signals or a change in surface properties, ${ }^{[9,11]}$ or on devices that release active substances. ${ }^{[7,36]}$ 
This chapter aims at providing the necessary biological background in order to understand the papers. It will describe devices that stimulate cells in culture, and also relate the devices to the corresponding biological events.

\subsection{Cell cultures}

Cell culture vessels are often dishes or flasks, commonly made of glass or plastics. Cell culture media - that is, physiological electrolyte often supplemented with amino acids, proteins, or other compounds - is added to provide the necessary nutrients for the cells. To provide the desired humidity and temperature, cell cultures are normally kept inside an incubator. Eukaryotic cells typically adhere to a surface within a few hours and start to proliferate. Cell cultures are used for in vitro experiments, where the cells originate from organs or tissue in animals. In contrast, in vivo experiments take place inside an animal. In complex organisms such as humans, many different cell types exist. Cells can differentiate, that is they become specialized. Differentiated cells combine to create tissues that in turn create organs.

\subsubsection{Cell signalling and communication}

In living organisms, biological systems are controlled by a complex variety of different signals, often originating from the blood stream, or carried by neurons. In addition, signals can be passed from one cell to a neighbouring cell or from the surrounding environment. These biological signals, whether chemical or electrical, are generally mediated by small molecules, ions and proteins. This biological signalling governs both the life-cycle of an individual cell and controls entire organs. A major challenge of in vitro models of biology is to provide signals that are similar to the ones occurring in vivo.

The outer part of the cell is composed of the cell membrane (figure 4.1), consisting mainly of a double layer of phospholipids. Various proteins are associated with the cell membrane, some, referred to as transmembrane proteins, span the entire membrane whereas others, called peripheral membrane proteins, are only linked to one side of the cell membrane. Carbohydrates are connected to some of the proteins on the outer side of the membrane and are important when cells interact with each other. An important class of transmembrane proteins are integrins, responsible for cell attachment. Some of the transmembrane proteins function as ion transport channels, others as receptors. When a specific messenger 
molecule binds to a receptor, an intercellular signal is mediated through the membrane and activates an intracellular pathway that conveys a response deeper into the cell.

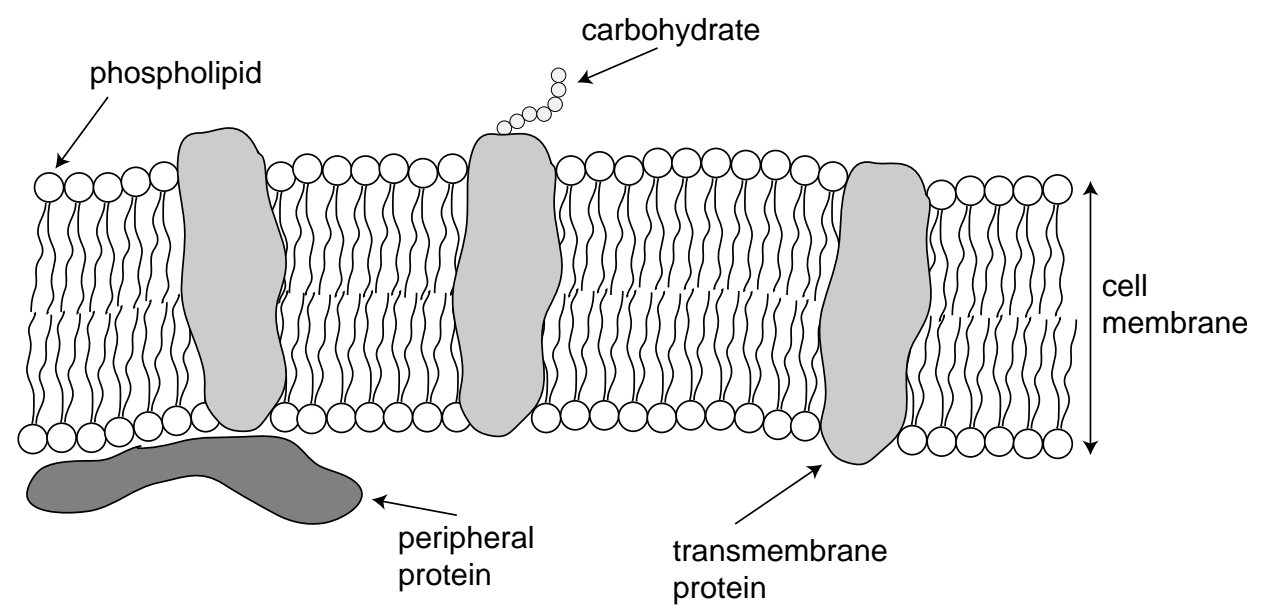

Figure 4.1 The cell membrane.

Cells are surrounded by the extracellular matrix that consists of various proteins and macromolecules. The most abundant proteins are collagen fibres that give structure. The matrix provides a scaffold for cell attachment and is also important for transmission of signals that regulate cell growth and function as well as morphology.

\subsection{Protein adsorption to polymer electrodes}

When proteins in aqueous solutions are exposed to a solid surface they will adsorb to it. ${ }^{[81]}$ The adsorption is governed by intermolecular forces including van der Waals, electrostatic and hydrophobic forces. ${ }^{[82]}$ Surface roughness is also of importance, ${ }^{[83,84]}$ and when adsorbing, the protein can change its conformation in order to minimize the free energy. ${ }^{[85]}$ Proteins are abundant in most biological fluids and will inevitably adsorb to electrodes in contact with the fluid during an experiment. Therefore, it is important to consider that, in most applications, proteins bind to the surface before cells do. In fact, surface-adhered proteins bind to cellular transmembrane proteins and regulate events such as cell adhesion and proliferation.

The amount of adsorbed proteins will depend on the chemical and physical properties of the exposed surface, ${ }^{[82]}$ and also on the type of protein. ${ }^{[86]}$ In general, more proteins adsorb on a hydrophobic than a hydrophilic surface. ${ }^{[87,88]}$ Highly 
hydrophilic surfaces, achieved for example by functionalization with polyethylene glycol, can thus be used to reduce protein adsorption. ${ }^{[89]}$

When it comes to conjugated polymer electrodes, it has been suggested that the type of counter ion used during synthesis plays a role in protein adsorption. ${ }^{[0]}$ By careful selection of counter ion, and hence surface chemistry, protein adsorption can be controlled. ${ }^{[82]}$ In addition, an applied potential generally increases protein adsorption. ${ }^{[86,91]}$ It has also been shown that protein adsorption to a conjugated polymer electrode can alter the electroactivity of the material. ${ }^{[2]}$

\subsection{Cell adhesion}

In vivo, cells can adhere either to other cells or to the extracellular matrix. The latter contains proteins, which bind to integrins in the cell membrane and thereby acts as anchors, keeping the cells in place. One of the most common of these anchoring proteins is fibronectin. When culturing cells on surfaces and in scaffolds in vitro, fibronectin is often added as a coating to provide the necessary anchors for cell adhesion. Different matrix proteins are also present in serum, a common supplement to cell culture media. There are a few different binding sites for intregrins on fibronectin, but one of the most important is the sequence containing the three amino acids arginine - glycine - aspartic acid (RGD). ${ }^{[33]}$ Cell adhesion to a surface is illustrated in figure 4.2.

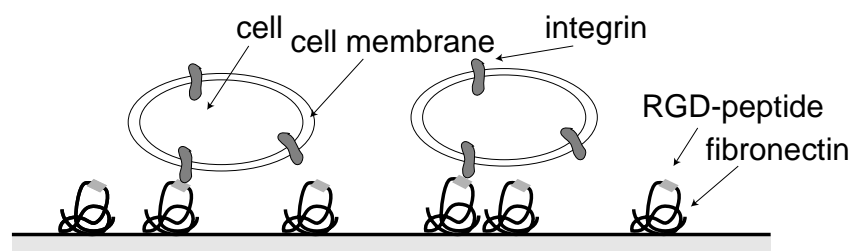

Figure 4.2 Cell adhesion to a surface.

As mentioned above, protein adsorption is crucial for cell adhesion. Therefore, a surface that is beneficial for protein interactions will most likely also be suitable as a cell culture substrate. Properties such as roughness ${ }^{[94]}$ and wettability ${ }^{[95]}$ are two examples of parameters that have been used to achieve control of cell adhesion. Conjugated polymers are good substrates for protein adsorption both due to their suitable chemical properties as well as their softness and flexibility. The importance of protein adsorption prior to cell adhesion has been shown in several studies, where cell adhesion to a conjugated polymer 
electrode improves radically when using a cell culture medium supplemented with serum. ${ }^{[11,96]}$ In particular, functionalizing a surface with the RGD peptide makes it possible for cells to adhere without presence of serum in the culture media. ${ }^{[97]}$ Many of the commonly used conjugated polymers lack available groups for covalent attachment of functional groups though. However, proteins and other biomolecules of interest can be incorporated as counter ions during electropolymerisation (see section 5.2.2), as they often carry negatively charged groups. ${ }^{[63,98,99]}$

Using conjugated polymers, it is also possible to influence cell adhesion through redox-induced changes in the chemical and physical properties of the surface. It has been shown that cell adhesion differs between oxidised and reduced PEDOT and polypyrrole surfaces. ${ }^{[1,96,100]}$ The suggested mechanisms involve mediation of cells through protein interactions with the surface.

\subsection{Stimulation and control of cells in culture}

Once cells have adhered to a surface, they will receive a multitude of signals that will determine their continued path. Cells can divide, spread, migrate, change their shape, grow and proliferate, and some may also differentiate. The signals and stimuli controlling these events are very complex and involve both cell-cell interactions and chemical and physical cues from the surrounding environment. An important class of biomolecules involved in chemical signalling for controlling cellular events are growth factors. A large number of growth factors with different functions exist, most of them are either proteins or hormones. In vivo, many growth factors are presented to cells while bound to extracellular matrix components. ${ }^{[101]}$ In vitro, growth factors and other soluble biomolecules can be supplemented to the cell culture media as chemical stimulation. In addition, chemical stimulation through the substrate is possible.

\subsubsection{Chemical stimulation}

The easiest way to chemically stimulate cells in culture is to add the reagent in question to the cell culture media. In other cases, more precise control of the delivery of active substances is required. This can be achieved by loading the substance to be delivered in a device that upon a certain trigger releases the active molecules. There is a wide variety of devices for such controlled delivery to cells, based on, for example, nanostructured materials, ${ }^{[102]}$ hydrogels, ${ }^{[103]}$ biodegradable 
materials, ${ }^{[104]}$ and membranes. ${ }^{[105]}$ A good delivery device should enable temporal and spatial control, and minimal passive release of active components before triggering.

When using conjugated polymers for controlled delivery the active molecule to be released can be incorporated during synthesis, either as a dopant or codopant. ${ }^{[106,107]}$ Upon electrochemical redox switching of the polymer, the active molecule is released as the polymer contracts (figure 4.3). A drawback with these devices is that the amount released is rather low.

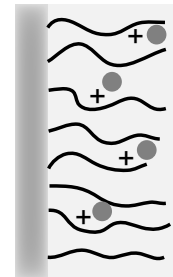

oxidised

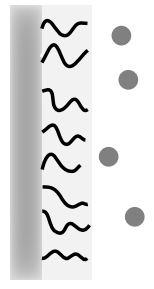

reduced

Figure 4.3 Release of a negatively charged active substance, incorporated as a counter ion, from a conjugated polymer upon reduction. The polymer contracts when reduced and the active substance (dark grey circle) is released as negative charges are no longer needed.

Other approaches have employed the redox dependent volume expansion of polypyrrole to create microvalves for delivery from reservoirs controlled by the valves, ${ }^{[108]}$ or to achieve controlled transport through a nanoporous membrane. ${ }^{[109]}$ In a final example, precise delivery can be achieved through an ionic transport device based on PEDOT. ${ }^{[110]}$

\subsubsection{Stimulation through the substrate}

Several parameters of the cell culture substrate can be employed to control cells, for example surface chemistry, ${ }^{[111,112]}$ elasticity ${ }^{[113,114]}$ and topography. ${ }^{[115,116]}$ Growth factors and other biomolecules can also be immobilized on the substrate. ${ }^{[117]}$

Using organic bioelectronics, direct electrical stimulation has been employed to increase neurite outgrowth on surfaces ${ }^{[9,118]}$ and to influence cell migration. ${ }^{[46]}$ Using polypyrrole, volume changes have been used to stretch cells, affecting intracellular signalling. ${ }^{[19]}$ It is also possible to incorporate growth factors and other active molecules during synthesis to control processes such as proliferation and differentiation. For example, extracellular matrix proteins used as counter ions in polypyrrole have been shown to effect proliferation and differentiation of myoblasts. ${ }^{[120]}$ Differentiation was also achieved on both polypyrrole and PEDOT 
doped with nerve growth factor. ${ }^{[75]}$ When using the biomolecule heparin as dopant, its surface exposure will vary depending on the redox state of the polymer. ${ }^{[63]}$ As heparin also binds several growth factors, redox switching can thus be used to control the amount of growth factors available to cells. ${ }^{[45]}$

\subsection{Cell detachment}

When cultured in vitro, the cells are often removed from the substrate either for reseeding or analysis. In addition to mechanical methods, the most common means of detaching cells is to target the cell membrane proteins involved in adhesion with enzymatic treatments (figure 4.4). The enzymes can however damage the cell membrane and extracellular matrix proteins. ${ }^{[121]}$ In order to avoid cell damage, alternative cell detachment methods are also in use. Integrins need $\mathrm{Ca}^{2+}$ in order to function, and $\mathrm{Ca}^{2+}$ chelating buffers like EDTA can therefore be used for cell detachment, but are rather inefficient compared to enzymatic methods.

a)

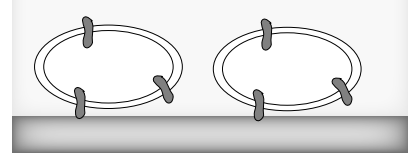

b)

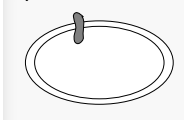

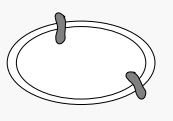

c)

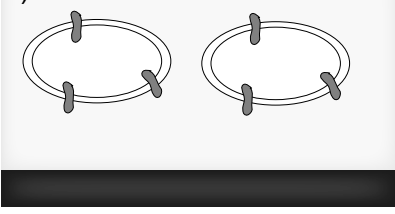

Figure 4.4 Cell detachment. In a), cells are growing adhered on a substrate. In b) cells are detached using an enzymatic method that damages surface proteins. In c), a noninvasive method is used that detaches cells through changes in the surface.

Another approach to cell detachment is to target the culture substrate, rather than the cells directly (figure 4.4c), thus enabling temporal and/or spatial resolution of the detachment. Thermoresponsive surfaces based on hydrogels have been used for detachment of cell sheets, and subsequently used for tissue engineering. ${ }^{[122]}$ When the temperature is lowered, the hydrophobicity of the hydrogel is altered and cells are detached. Other alternative detachment methods rely on detachment cues based on magnetism, ${ }^{[123]}$ ultra-sound ${ }^{[124]}$ and electronic signals. Electroactive self-assembled monolayers (SAMs) can be synthesized with the RGD peptide to promote cell adhesion. Upon electrochemical activation, the SAMs are cleaved and cells will detach. ${ }^{[125-127]}$ Further electronic examples include polyelectrolytes that support cell adhesion, but desorb upon electrochemical oxidation of a conducting substrate underneath, ${ }^{[128]}$ and we have shown a conjugated polymer that detaches upon oxidation, taking cells with it. This is discussed further in Paper IV. ${ }^{[129]}$ 
With substrates that can be patterned into individually addressable areas, selective cell detachment can be achieved. This has been shown both with thermoresponsive surfaces ${ }^{[122]}$ as well as with electroactive SAMs. ${ }^{[130]}$ Depending on the size of the pattern, the detachment can target cell populations of various sizes, all the way down to individual cells.

\subsection{Structure and adhesion of bacteria}

The field of microbiology studies organisms like fungi, viruses and bacteria. Bacteria can cause diseases, but may also be extremely useful to humans, for example in both food and drug production, and they are essential components of many ecosystems. Controlling their growth is therefore of great interest.

a)

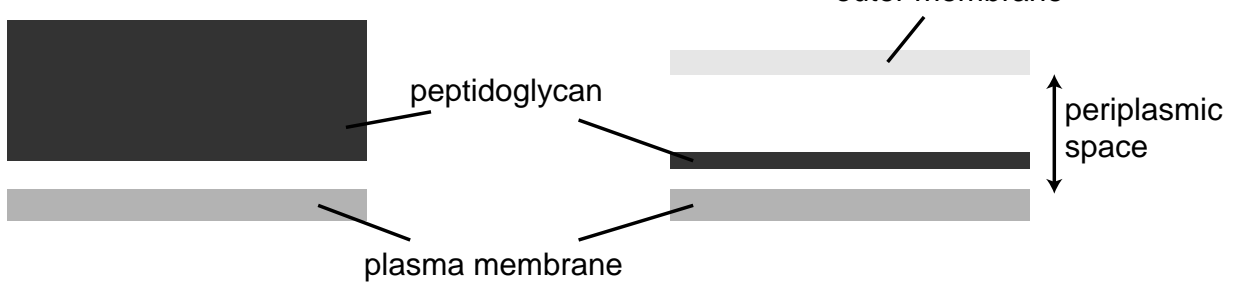

Figure 4.5 Schematic picture of the bacterial cell wall for a) gram-positive and b) gramnegative bacteria

Prokaryotic cells, like bacteria, differ from eukaryotic ones in several ways. Bacteria are surrounded by a cell wall, underneath which is a plasma membrane, similar to the cell membrane surrounding eukaryotic cells. The cell wall gives bacteria shape and structure as well as protection from toxins, but it also provides action sites for antibiotics. Depending on the cell wall, bacteria are classified as either gram-negative or gram-positive. A gram-positive cell wall consists of a thick peptidoglycan layer (figure 4.5a), whereas a gram-negative cell wall is divided into an outer membrane and a peptidoglycan layer, separated by the periplasmic space (figure $4.5 \mathrm{~b}$ ). The outer membrane in a gram-negative cell is linked to the peptidoglycan layer by lipoproteins. It also contains lipopolysaccharides that projects from the surface, providing a defence system and giving the bacteria negative surface charge. A number of additional structures outside the cell wall provide the bacteria motility and aid in attachment to solid surfaces.

Bacterial adhesion is controlled by much the same forces as for eukaryotic cells; it is influenced by properties such as hydrophobicity, ${ }^{[131]}$ surface charge ${ }^{[132]}$ 
chemical composition ${ }^{[133]}$ and surface roughness. ${ }^{[134]}$ However, proteins are of less importance when it comes to bacterial adhesion. ${ }^{[135]}$

\subsubsection{Biofilm formation}

Once bacteria have attached on a surface with water and nutrients present, a biofilm may form. A biofilm is composed not only of both live and dead bacteria but also contains proteins, polysaccharides and nucleic acids within a closed matrix. The first bacteria that adhere start producing polysaccharides that will form the matrix, building up a biofilm ${ }^{[136]}$ (figure 4.6). The matrix is also important for attachment to the underlying surface. The mature biofilm will provide protection against immune responses and antimicrobial agents, and is therefore of importance for bacterial survival. Biofilm formation is a source of persistent infections ${ }^{[137]}$ on medical devices such as catheters and implants, and it is also a problem in the food industry. However, in microbial fuel cells bacteria and biofilms are utilized advantageously for energy production. ${ }^{[138]}$

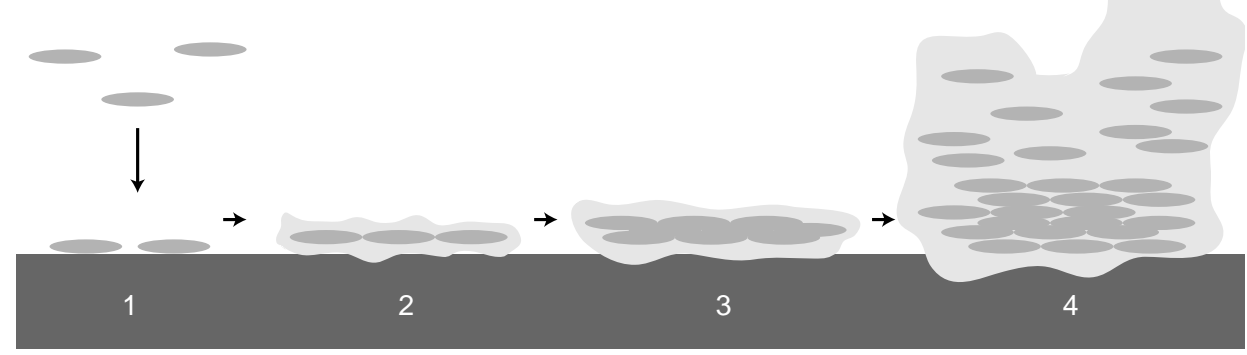

Figure 4.6 Biofilm formation on a solid surface. Bacteria adhere to the surface (1), forming a monolayer and slime (2), then colonies and multilayers are formed (3) and finally a mature biofilm (4).

The formation and composition of the biofilm is strongly influenced by the environment, including the surface, and parameters such as temperature and availability of nutrients. As biofilms are a major source of infections in healthcare, significant research has focused on preventing their formation. As the first step in biofilm formation is adhesion of bacteria, prevention of attachment or removal of adhered bacteria decreases the risk of infection. Traditional ways of removing bacteria are through heat, radiation or chemical sterilization. Current research in preventing bacterial adhesion and subsequent biofilm formation, focuses on various surface modifications, ${ }^{[133]}$ a common one being the use of highly hydrophilic surfaces. ${ }^{[139,140]}$ Others use charged polymers, ${ }^{[141]}$ changes in surface hydrophobicity ${ }^{[142]}$ or a combination of both. ${ }^{[143]}$ There are also applications 
involving conjugated polymers, to combine surface effects with an applied electric potential. ${ }^{[144]}$ All in all, it has proved extremely difficult to completely avoid bacterial adhesion, one reason being the very rapid adjustments made by bacteria in order to survive. 


\section{EXPERIMENTAL METHODS}

Several different experimental methods have been used in the work presented in this thesis. The methods can broadly be divided into three categories; polymerisation, characterization and microprocessing. They will be described further below.

\subsection{Chemical polymerisation}

The process of forming a polymer by connecting a large number of monomers is known as polymerisation. The first step in creating the covalently-linked polymers described in this thesis is generally the oxidation of a monomer, forming a radical
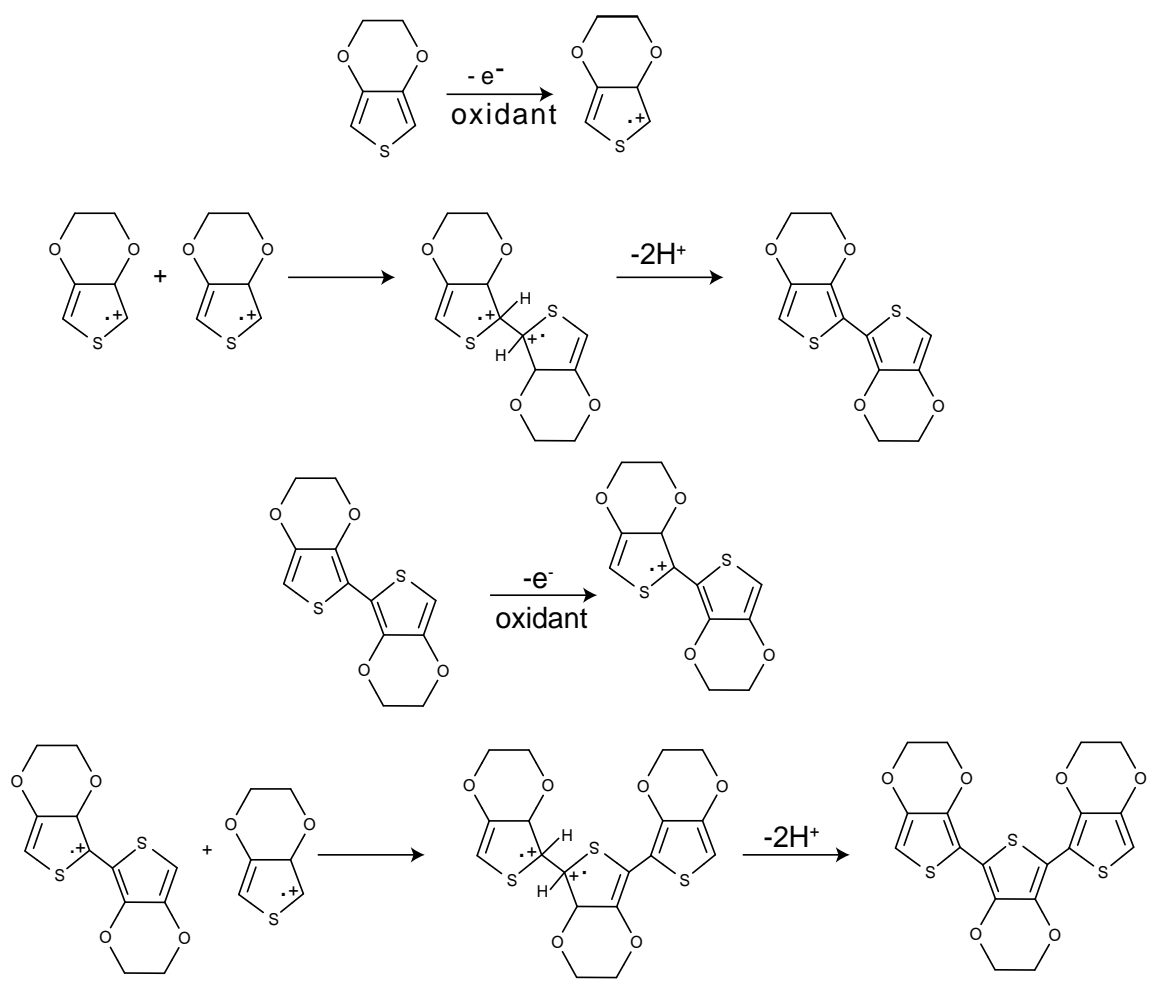

Figure 5.1 Chemical polymerisation of EDOT. 
cation. This radical can then react with another monomer, creating a dimer and subsequently longer chains (figure 5.1). In order to oxidise the monomer, an oxidant is required. Commonly, iron salts like iron tosylate and iron chloride are used, with iron being reduced from $\mathrm{Fe}^{3+}$ to $\mathrm{Fe}^{2+}$. The anion (e.g., tosylate) is incorporated as counter ion in the resulting polymer. A weak base is also needed to take up protons released in this process and to stabilize the dimer. ${ }^{[145]}$ In chemical polymerisation the monomer and oxidant are mixed, requiring a solvent suitable for both species. By varying oxidant, base and solvent used, polymers with different properties can be prepared. An example of a polymer produced by chemical polymerisation is PEDOT:PSS, where the polymerisation is carried out in an aqueous polyelectrolyte (PSS) with $\mathrm{Na}_{2} \mathrm{~S}_{2} \mathrm{O}_{8}$ as the oxidant. ${ }^{[39]}$ PEDOT-S is also synthesised by chemical polymerisation, starting from the monomer EDOT-S and using both $\mathrm{FeCl}_{2}$ and $\mathrm{Na}_{2} \mathrm{~S}_{2} \mathrm{O}_{8}$ as oxidants.

\subsubsection{Vapour phase polymerisation}

Vapour phase polymerisation (VPP) is a special variation of chemical polymerisation. It was first developed for polypyrrole, ${ }^{[146]}$ but has subsequently been extensively used for PEDOT. ${ }^{[147]}$ In VPP, the substrate is first coated with an oxidant solution and dried. The coated substrate is then placed in the top of a polymerisation chamber, with the monomer solution in the bottom (figure 5.2).

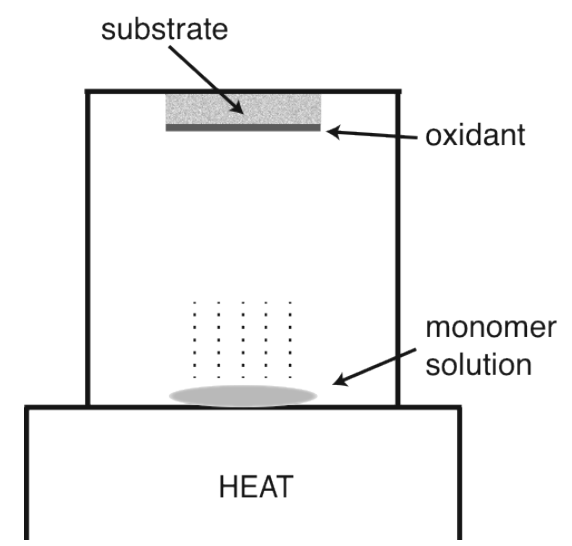

Figure 5.2 Setup for VPP. Monomer is placed in the bottom of the chamber on top of a hotplate and the substrate, coated with oxidant, is placed in the top.

Depending on the polymer, heating might be required to start the polymerisation process where monomer is evaporated and reaches the substrate. The vapour phase monomers will subsequently react with the oxidant and 
polymerise on the substrate. By careful selection of additives and polymerisation parameters, PEDOT films with conductivities above $1000 \mathrm{~S} \mathrm{~cm}^{-1}$ have been prepared using VPP. ${ }^{[148]}$

To produce better quality films, a weak base like pyridine can be added to the oxidant solution. ${ }^{[149]}$ It will increase the $\mathrm{pH}$, which slows down the reaction and prevents acid-initiated polymerisation that results in lower conductivity films. Water is needed as a proton scavenger during polymerization, and without water no polymer is formed. ${ }^{[150]}$ VPP can be performed both at atmospheric pressure and in vacuum. The latter is faster but requires additives as water is not present. ${ }^{[151]}$

Compared to chemical polymerisation, VPP generally results in better quality films with higher conductivity. It can also be performed on a large variety of substrates, including 3D-scaffolds ${ }^{[152]}$ and it is not dependent on monomer and oxidant being mixed in the same solvent.

\subsection{Electrochemical methods}

Electrochemical methods can be used both for polymerisation and to characterise various properties of the resulting polymer films. Typical characterisation methods follow the potential or current over time or upon a change in one of the parameters. Cyclic voltammetry, where the potential is measured while sweeping the current, is another common method for investigating the electrochemical properties of conjugated polymers.

\subsubsection{Three-electrode setup}

To achieve high control of the applied potential in electrochemical experiments, a potentiostat with a three-electrode setup is generally employed (figure 5.3). The three electrodes are placed in a common electrolyte, where the working electrode is the one where the electrochemical reaction occurs. In the case of conjugated polymers, the polymer itself constitutes the working electrode. The potentiostat maintains a constant applied potential between the working electrode and a reference electrode with a constant internal potential. The current needed to maintain the potential is injected through the counter electrode, typically an inert metal, and is measured between the working and counter electrodes. In a threeelectrode setup, the applied potential is always stated versus the internal potential of the reference electrode, e.g., volts versus $\mathrm{Ag} / \mathrm{AgCl}$. If instead using a two- 
electrode setup lacking a reference electrode, the exact potential at the working electrode cannot be determined, as the potential across the entire cell is measured.

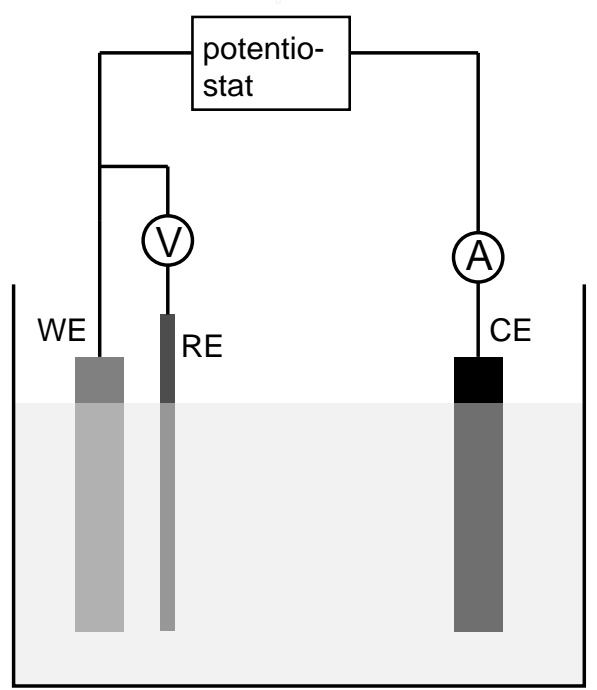

Figure 5.3 Three-electrode setup with a potentiostat. The electrodes; working electrode $(\mathrm{WE})$, reference electrode $(\mathrm{RE})$ and counter electrode $(\mathrm{CE})$ are placed in an electrolyte.

\subsubsection{Electropolymerisation}

In addition to chemical polymerisation where an oxidant is added to oxidise the monomers, electrochemical oxidation is possible. In this case a conducting substrate is submerged in a solution containing monomer and an electrolyte, often as the working electrode in a three-electrode setup (figure 5.3). When an electric potential above the oxidation potential of the monomer is applied, electrons will be removed from the monomers close to the working electrode, these can then react to form a polymer film that will be deposited on the electrode surface. Anions from the electrolyte will be incorporated as counter ions.

The exact mechanism for electropolymerisation is not known, but the most commonly proposed one ${ }^{[153,154]}$ is described in figure 5.4 . The mechanism was first presented for polypyrrole, but PEDOT supposedly follows a similar route. In the first step, a monomer is oxidised by the applied potential at the electrode surface, creating a cation radical. As the electron transfer reaction is significantly faster than the diffusion of monomers to the electrode surface, all monomers close to the surface will be oxidised. Two cation radicals can undergo dimerization to form a dication, which upon loss of two protons becomes a dimer. The dimer can in turn be oxidised, and has a lower oxidation potential than the monomer due to 
delocalization of the electrons. The dimer radical cation can react with a monomer radical cation to form a trimer and so on until polymer chains are formed. The final polymer will be in its oxidised form, with approximately one positive charge per three to four monomer units. ${ }^{[153]}$

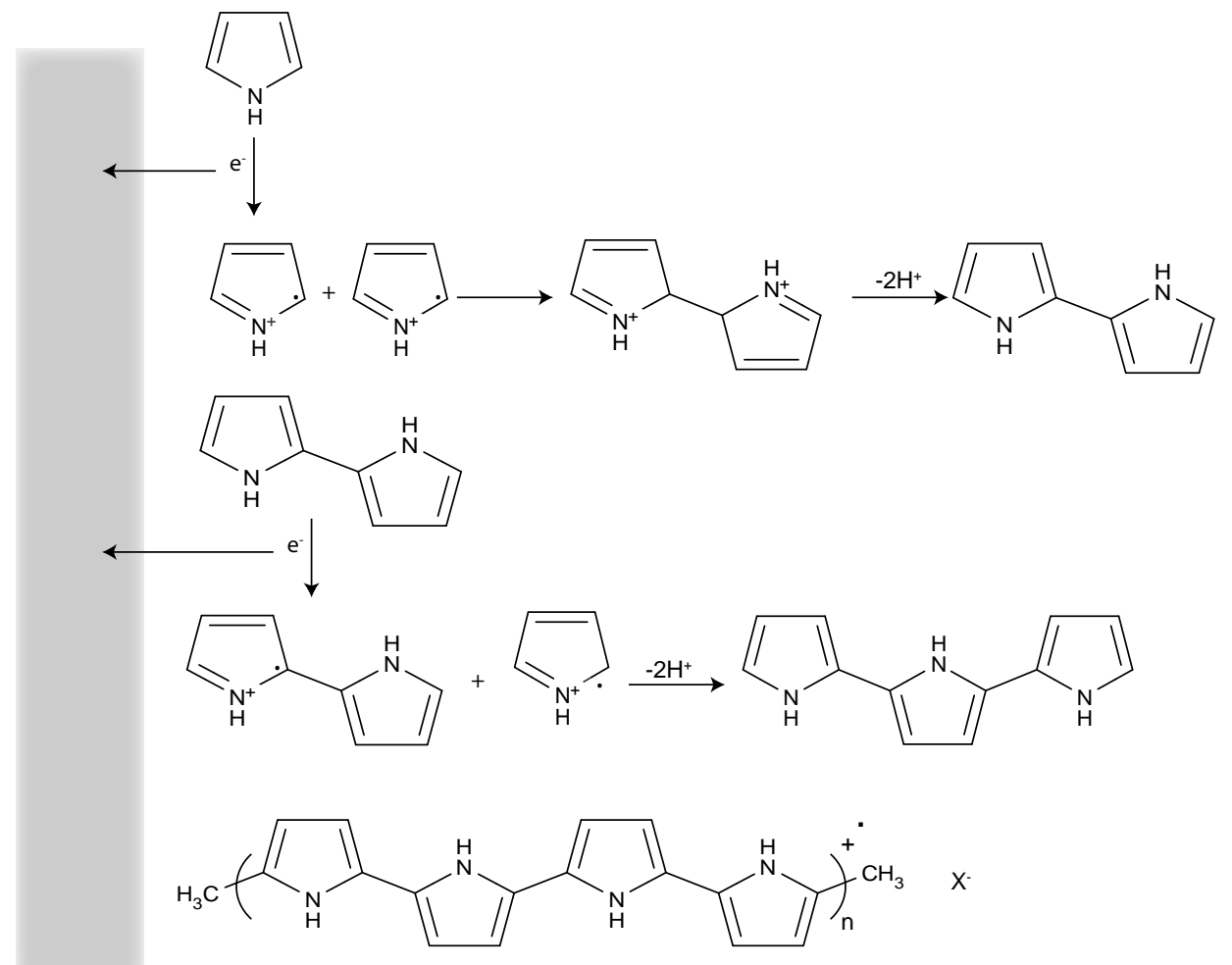

Figure 5.4 Electropolymerisation of polypyrrole. The monomer is oxidised while donating an electron to the electrode on the left.

For some monomers, like pyrrole, coupling might occur at undesired positions on the monomers, resulting in polymers with poor characteristics. In EDOT, this is prevented by the 3,4-substitution to the thiophene backbone, ${ }^{[40]}$ making electropolymerisation of highly conducting PEDOT films with good order possible.

The deposition of the forming polymer occurs through a nucleation and phase-growth mechanism. Depending on the monomer used, either nucleation is instant with three-dimensional growth, ${ }^{[155,156]}$ or successive with two-dimensional growth. ${ }^{[157]}$ Nucleation most likely occurs through absorption of oligomers and monomers from solution and/or by addition of monomers to already absorbed 
polymer chains. ${ }^{[158,159]}$ After nucleation, polymer chains continue to grow and in some cases form networks.

The properties of the resulting electropolymerised film will depend on a number of parameters such as solvent, ${ }^{[160]}$ concentration of monomer and counter ion, ${ }^{[161]}$ type of counter ion, ${ }^{[162]}$ temperature, ${ }^{[163]} \mathrm{pH},{ }^{[164]}$ applied potential ${ }^{[165]}$ and polymerisation method. ${ }^{[166]}$ By varying these parameters, films with differences in morphology, thickness, conductivity and adhesive properties can be produced. Three different electropolymerisation methods are generally used: constant current, constant potential, and cyclic voltammetry. The solvent used during electropolymerisation can be either aqueous or organic. When wanting to use biomolecules as counter ions, water is often required. Surfactants can be added to circumvent the low monomer solubility in water, ${ }^{[160,167]}$ but it is also possible to dissolve sufficient amounts of monomer with long stirring times. ${ }^{[45,168]}$ The applied potential must be above the oxidation potential of the monomer but sufficiently low to avoid overoxidation, ${ }^{[169]}$ which results in non-conducting films. The thickness will depend largely on the charge passed during polymerisation, but also on the counter ion. ${ }^{[98,170]}$

Compared to other polymerisation methods, electropolymerisation allows for the utilization of a larger variety of counter ions as it is possible to use aqueous electrolytes. For example, using biomolecules as counter ions, ${ }^{[45,98,171]}$ it is possible to prepare suitable polymer surfaces for bioelectronics applications. The major drawback of electropolymerisation is that an electrically conductive substrate must be used.

\subsubsection{Cyclic voltammetry}

In cyclic voltammetry $(\mathrm{CV})$, the potential is swept between two values using a constant scan rate while the current is measured. A three-electrode setup with a potentiostat is typically used. CV is a commonly employed method to evaluate the electrochemical properties of conjugated polymer films. When sweeping first to a positive and then to a negative potential, the doping and de-doping of the polymer can be followed. A typical CV scan of PEDOT is shown in figure 5.5.

The anodic and cathodic current peaks are typically well separated and different in shape. The broad shape of the peaks may depend on the different chain lengths and hence different oxidation potentials of the polymer chains within the film. ${ }^{[172]}$ The hysteresis observed can be explained by structural changes leading to improved interactions between different chains and thus stabilization. ${ }^{[173]}$ During a 
CV scan, ions must be inserted or expelled from the film to maintain electroneutrality. Generally, diffusion of ions to the film is slower than the transfer of electrons, making the CV diffusion limited, especially at high scan rates. In addition to the scan rate, the type of counter ion within the film, the solvent and the electrolyte will largely influence the shape of the curve.

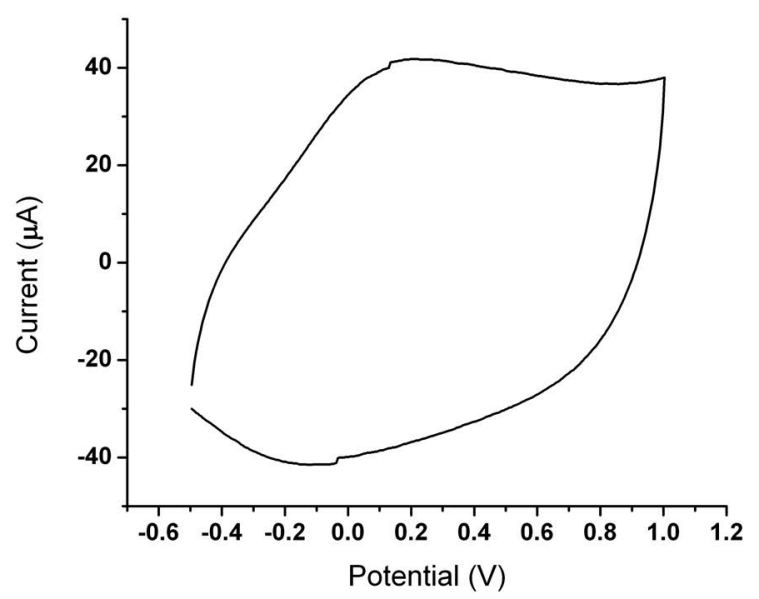

Figure 5.5 CV of PEDOT-S in $0.1 \mathrm{M} \mathrm{LiClO}_{4}$ in acetonitrile. The scan rate was $0.7 \mathrm{~V} \mathrm{~s}^{-1}$.

\subsection{Processing methods}

Polymers are often processed from solution and the first step is typically to cast thin films. There are several methods for doing this including drop-casting, spin coating and bar coating. In addition, many polymers can be printed using a variety of techniques. The polymer films can be subsequently processed into devices using for example photolithography in combination with etching.

\subsubsection{Spin coating}

Spin coating is a common method to create a thin uniform film on a substrate. The substrate is placed on a chuck and held in place by vacuum (figure 5.6). The material to be coated is usually dissolved in a volatile solvent, and the solution is placed on the substrate. It is then distributed all over the substrate by rotation at high speed. The centrifugal force creates a thin film, and the solvent is evaporated until a solid film is formed. The thickness of the resulting film depends on the spinning speed, concentration of material (viscosity) and type of solvent. 


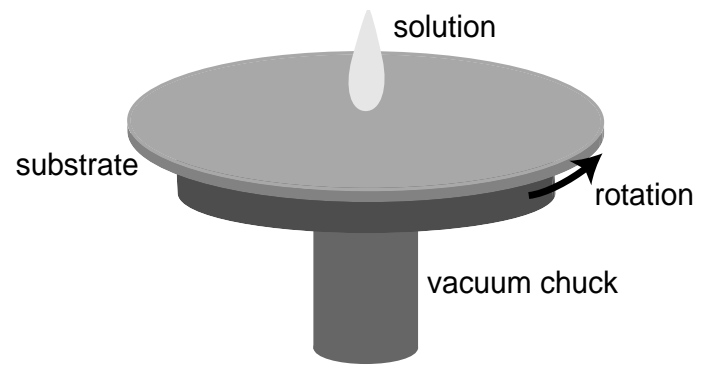

Figure 5.6 Spin coating. The solution is applied on a substate, placed on a vacuum chuck. When the rotation is started, the solution is spread and a film is formed.

\subsubsection{Bar coating}

Bar coating, also known as Meyer rod coating, is another coating method where a wire-wound rod is used to create thin uniform films on flat substrates (figure 5.7).

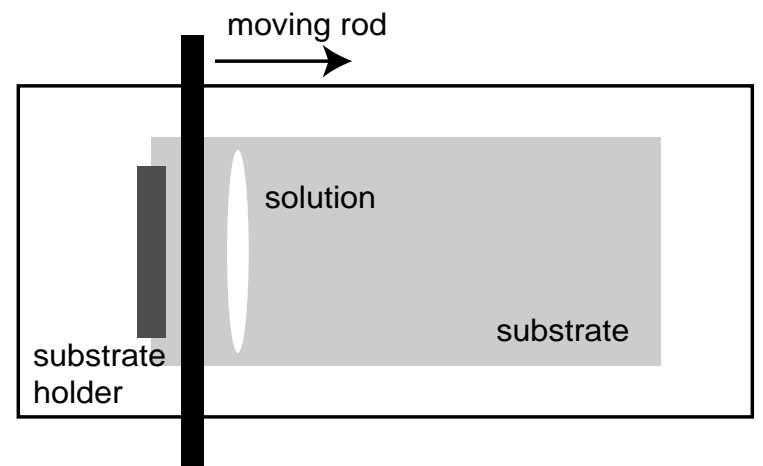

Figure 5.7 Bar coating. A moving rod is distributing the coating solution on the substrate.

The rod is placed on the substrate, and the solution to be coated just in front of it. As the rod is moved along the substrate either manually or automatically, the solution is distributed to create a thin film. The thickness of the wire around the rod, together with the speed of the rod and the concentration of the solution, determines the thickness of the resulting film. Thinner wires will give a thinner and more uniform film due to the smaller volumes of space available for solution between adjacent windings.

\subsubsection{Photolithography}

Photolithography is widely used in microfabrication and in the semiconductor industry for patterning. It utilizes light-sensitive chemicals called photoresists to create patterns on a substrate. First, a photoresist is spin coated on the substrate. Next, the photoresist-covered substrate is exposed to UV-light through a photo- 
mask with a pattern that protects certain parts and leaves others bare (figure 5.8a). In a positive photoresist, the exposed parts become soluble and are removed using a developer whereas the non-exposed parts remain insoluble. Alternatively, in a negative photoresist the exposed parts become insoluble and the non-exposed parts are removed using a developer. The photoresist can either remain on the device or be used as protection during subsequent etching steps and then removed. A single device may require several photolithography steps that need to be aligned on top of each other. Resolution depends on many different parameters such as the hardware, the materials and processing conditions used. For high resolution, materials with good stability that do not swell during processing should be used.

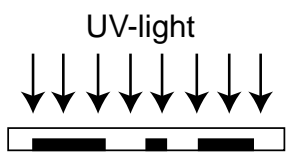

a)

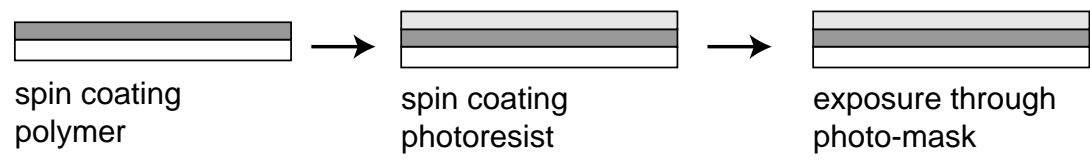

after developing

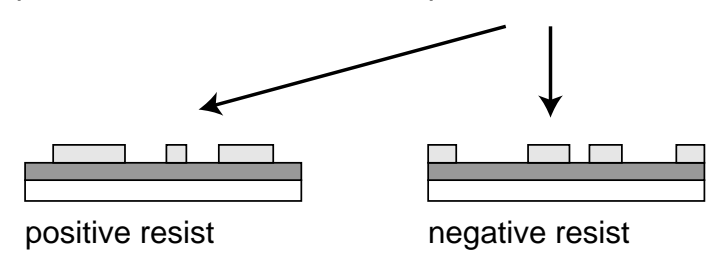

RIE

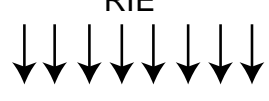

b)
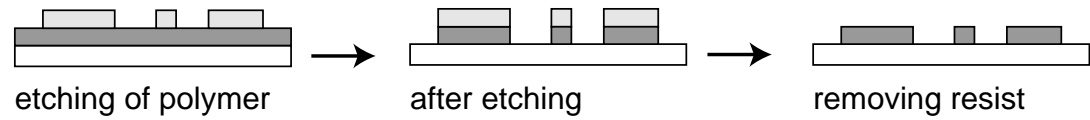

Figure 5.8 Photolithography (a) and reactive ion etching (b) of a polymer film. In b) a positive photoresist is used.

\subsubsection{Subtractive techniques}

After exposure and development of a photoresist layer over a thin film of polymer or metal, a resist pattern remains. This can be used for protection while performing subtractive techniques to remove the exposed parts of the film. After removal of the resist, a pattern in the film remains (figure 5.8b). For metals, wet etching is typically used. The substrate is submerged in a chemical solution that reacts with the exposed metal and removes it. Reactive ion etching (RIE) is a dry etching 
method commonly used in microfabrication. A chemically reactive plasma is generated in vacuum by a high electromagnetic field between two electrodes. Ions are accelerated towards the substrate (placed on the bottom electrode) and react with it, removing exposed parts. As ions only hit the substrate vertically, etching is highly anisotropic. Different gases can be combined in RIE, and for etching of polymers a mixture of $\mathrm{O}_{2}$ and $\mathrm{CF}_{4}$ is typically used.

\subsubsection{Additive techniques}

Apart from spin coating, there are a number of other techniques commonly used in microfabrication for material deposition on a substrate. These are typically used for metals and other solid compounds. Two common ones are chemical vapour deposition (CVD) and physical vapour deposition (PVD), both performed in the gas phase. In CVD, the substrate is exposed to volatile precursors that react and form a film on the surface. One example is the deposition of silicon and silicon oxide on wafers. Typical PVD processes are sputtering and thermal evaporation. In PVD, no chemical reactions take place; the deposition occurs when the material in its gas phase is condensed onto the substrate. 


\section{DEVICES}

Several different devices have been used in the papers presented in this thesis. They vary from simple surface switches with one polymer electrode oxidised and the other reduced in a three-electrode setup, to more complex matrix structures prepared by photolithography. This chapter will briefly describe the devices and the fabrication processes used to realize them.

\subsection{Surface switches}

An organic electronic surface switch consists of two polymer electrodes, often made on the same substrate but separated by a disruption in the active polymer film. The planar surface switch (shown in figure 3.2) has been used to investigate how the polymer's redox state influences cell adhesion. ${ }^{[11,100]}$ However, a planar setup is not always wanted, and sometimes only one active electrode is required. Therefore the surface switch was divided into two separate electrodes that were placed either in the bottom of a dish (papers II, IV, VI) or glued along the sides of a well (paper I). The devices are shown in figure 6.1.

a)

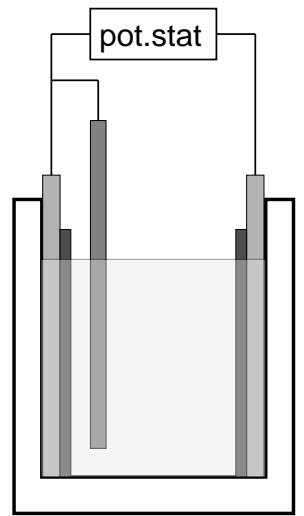

b)

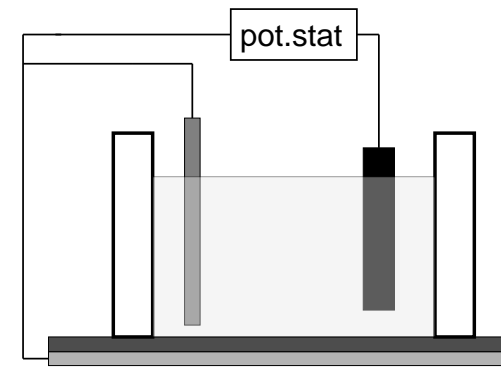

Figure 6.1 Devices used in papers I (a), II and IV (b). In both cases, the active polymer (dark grey) is polymerized on top of PEDOT:PSS (light grey). In a), polymer electrodes are glued along the sides of a plastic well, a reference electrode (grey) is placed in the electrolyte. In b), the active polymer is placed in the bottom, and a plastic ring is glued on top to create a chamber that is filled with electrolyte. In the electrolyte a reference electrode and a metal counter electrode (black) are placed. 
When only a single electroactive polymer electrode was desired, for example when investigating the electrochemical properties, a metal counter electrode was used. As transparent and flexible substrates were required, PEDOT:PSS-coated PET foil was used as the conductive substrate for electropolymerisation (paper I, II). In the detachment experiments (paper IV), a conductive substrate was needed to ensure that all parts of the PEDOT-S:H film was addressed also during cracking, and again PEDOT:PSS-coated PET foil was used to provide the necessary transparency and flexibility. In all cases, a $\mathrm{Ag} / \mathrm{AgCl}$ reference electrode was included for precise control of the applied potentials.

\subsection{Matrix structures}

An electronic matrix typically consists of pixels of equal size organized in columns and rows. The pixels are individually addressed either through "passive" or "active" techniques. In passive addressing, all pixels in one row (or column) are connected. By simultaneously addressing one column and row, the pixel at the intersect is turned on. However, there is a significant risk of partially addressing pixels near the intersect, so called "cross-talk", in this scheme. In active addressing, only one pixel is addressed. This is typically achieved by either individual wiring for each pixel or including one or more transistors or other circuit elements at each pixel. The control is better, but the manufacturing becomes more complicated when compared to a passive matrix.

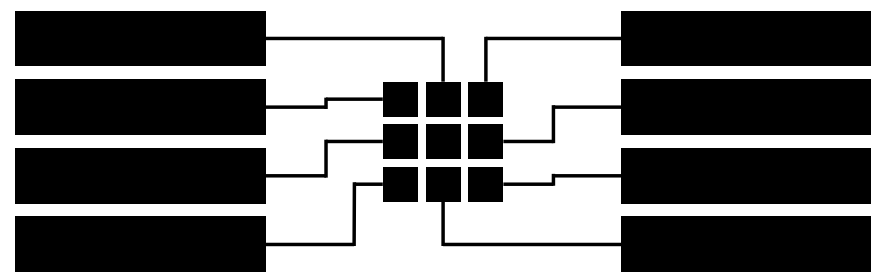

Figure 6.2 Matrix structure used in paper IV

In paper IV, a simple active matrix was used for selective detachment of PEDOT-S:H (figure 6.2). Each pixel was addressed by patterned lines making the pixels individually addressable. Only a $3 \times 3$ matrix was realized, since larger structures would require addressing lines between the pixels. This would interfere with the function of the device as the pixel area would decrease. The matrix was patterned using photolithography in combination with reactive ion etching, in one step on PEDOT-S:H bar coated on top of PEDOT:PSS-coated PET foil. 
In order to make larger matrices and to minimize the necessary gaps between the individual pixels a simple active matrix device was realized for selective detachment of PEDOT-S:H and cells (paper VI). Each PEDOT-S:H pixel in the matrix was addressed by a gold pad, placed between two resistors, in turn connected to one of the common gold connectors for each row or column. The connectors were separated at the crossings by insulating pads. A $2 \times 2$ matrix is depicted in figure 6.3. The gold connectors and resistors were placed in an encapsulated backplane underneath the pixels. PEDOT-S:H only detaches at a potential higher than $+0.7 \mathrm{~V}$, and that fact was utilized in the matrix. The resistors ensured that the potential reaching the pixel was average of the two applied. By applying negative potentials to all rows and columns except the ones corresponding to the pixel to be detached, potentials were kept below the threshold for detachment at all other pixels.

a)

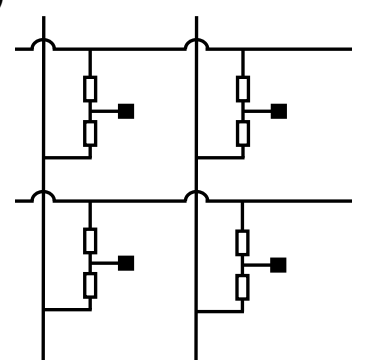

b)

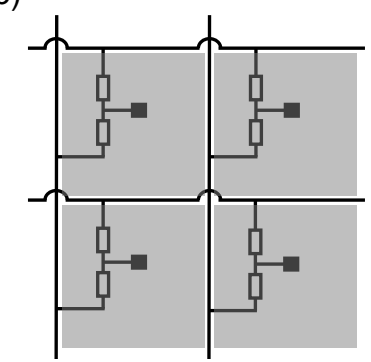

c) $-0.5 \mathrm{~V}$

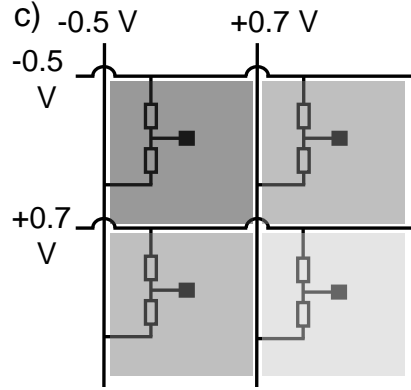

Figure 6.3 Matrix structure used in paper VI. The backbone structure with gold connectors and resistors (a) with PEDOT-S:H added on top (b) and with an applied potentials to make the lower right pixel detach (c).

\subsubsection{Fabrication of matrix device}

The fabrication process of the simple active matrix device used in paper VI is described in figure 6.4 and briefly in the following text. First, gold (with titanium as adhesion layer) was evaporated on a glass wafer. The gold was patterned using photolithography and wet etching into all gold wiring except the connections over the crossings on the rows. Next, the negative photoresist SU-8 was patterned as insulating pads at the crossings. Then a second layer of gold (again with titanium as adhesion layer) was evaporated and patterned to realise lines on top of the SU-8 pads. In the next step, PEDOT:PSS resistors were created using photolithography and reactive ion etching. Then a second layer of SU-8 was added to encapsulate both gold and resistors, leaving an opening for connection between the gold and the active layers. Finally, a layer of PEDOT:PSS and a top layer of PEDOT-S:H 
were added and patterned into the active pixels using photolithography and reactive ion etching.

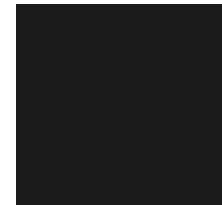

evaporation of gold

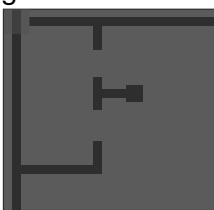

evaporation of gold

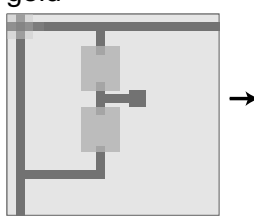

coating of SU-8

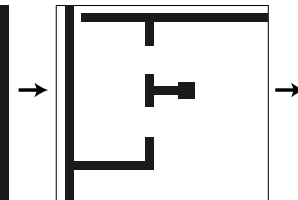

patterning and etching of gold

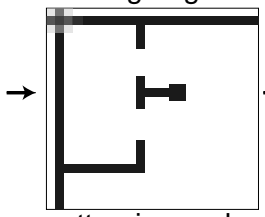

patterning and etching of gold

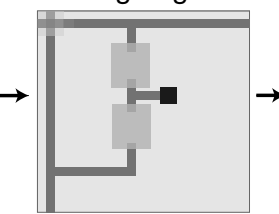

patterning of SU-8

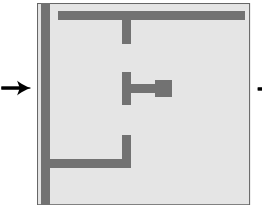

coating of SU-8

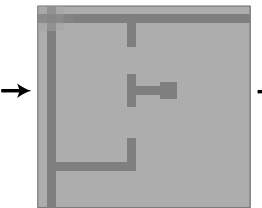

coating of PEDOT:PSS

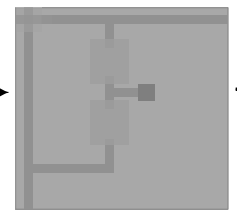

coating of PEDOT:PSS and PEDOT-S:H
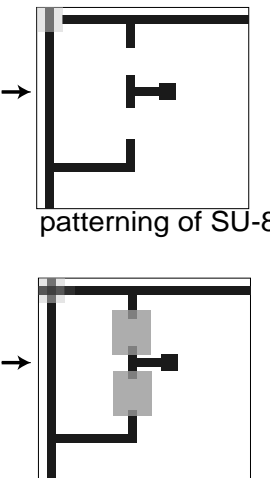

patterning and etching of PEDOT:PSS

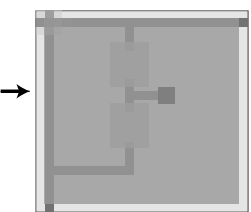

patterning and etching of PEDOT:PSS and PEDOT-S:H

Figure 6.4 Fabrication of the passive matrix device used in paper VI. For simplicity, only one pixel is shown. For further details see text or the paper. 


\section{CONCLUSIONS AND FUTURE OUTLOOK}

This thesis focuses on electronic control of cell cultures using surfaces composed of conjugated polymers. It is shown that through variation of polymer, counter ion, synthesis method and applied potential, cellular activities such as adhesion, differentiation and detachment can be controlled.

Previous work in our group, performed in collaboration with cell biologists at Karolinska Institutet in Stockholm and the Health University in Linköping, had focused on control of eukaryotic cell adhesion using PEDOT:tosylate surfaces prepared by chemical polymerisation. In Paper I we replaced PEDOT:tosylate electrodes with electropolymerised PEDOT in order to be able to include relevant counter ions. The electrodes were used to modulate bacterial adhesion and subsequent biofilm formation. Heparin and dodecylbenzene sulphonate were chosen as counter ions as they potentially have a negative effect on bacterial growth. Significant differences were observed for biofilm formation depending on redox states, with more forming on oxidised than on unswitched and reduced electrodes. This might be due to differences in hydrophobicity, PEDOT microstructures or surface exposure of the counter ions, depending on redox state.

While working with PEDOT:heparin and biofilm formation, we found that the surface exposure of heparin's sulphate groups increases when reducing PEDOT, most likely due to weaker interactions with the neutral PEDOT backbone. This was investigated further in Paper II, where the changes in heparin exposure enabled subsequent control of heparin-binding growth factors, in turn important for neural stem cell differentiation. A clear redox state-dependent effect was seen on neural stem cells cultured on PEDOT:heparin electrodes. On reduced PEDOT:heparin there was no need to add soluble growth factor to the cell culture medium in order to keep the stem cells in their undifferentiated state. When oxidising the PEDOT:heparin electrode however, the amount of available growth factor decreased and stem cells began differentiating. In the future, we see other potential uses of polymer systems like these, where the interaction between PEDOT, or some similar conjugated material, and its counter ion can control surface binding and exposure of other molecules. 
Papers I, II and III clearly show that the choice of synthesis method and counter ion can influence the properties of the resulting films. This opens up possibilities for future experiments extending combinations between polymer and biologically relevant counter ions to achieve suitable materials for control of cell cultures. Of particular relevance to future efforts will be the use of vapour phase polymerisation in combination with electropolymerisation, enabling coating on scaffolds with 3D-geometries to further mimic in vivo conditions.

The last papers in the thesis focus on cell detachment. Unsuccessful attempts of controlling cell detachment had previously been made in the group using PEDOT electrodes. When instead testing a water-soluble and self-doped PEDOT derivative (PEDOT-S) we found that a thin film could be detached when oxidised. If $\mathrm{Na}^{+}$was replaced with $\mathrm{H}^{+}$as charge balancing ions to the sulphonate groups during synthesis (PEDOT-S:H), adhesion characteristics before detachment were improved even further. We characterized the properties of detachment thoroughly (Paper IV and V) and found that detachment depended on the type and concentration of electrolyte, the applied potential, temperature and $\mathrm{pH}$. Importantly, PEDOT-S:H only detached at potentials above a certain threshold value. The proposed detachment mechanism is based on polymer swelling during oxidation due to inflow of anions and water from the electrolyte, followed by reorientation of the polymer chains due to more self-doping, in turn inducing strain within the material.

Human kidney epithelial cells could be detached using PEDOT-S:H films (Paper IV). However, we soon realised that the serum-supplemented cell culture medium - or rather the serum proteins - hindered detachment (Paper VI). After shorter cultivation times, the problem could be solved by replacing the supplemented medium with buffer or new, non-supplemented, medium when detaching the cells. As PEDOT-S:H is water-soluble it is possible to add biologically relevant substances directly to the polymer solution. If the properties are conserved after processing, functionalities omitting the need for serum supplementation might be added.

PEDOT-S:H can be patterned using standard photolithography. In Paper VI a simple actively addressed matrix device intended for selective cell detachment was realised. The matrix is based on a resistor network to ensure that only selected pixels reach the threshold potential for detachment. The matrix device was used for detachment of human primary keratinocytes and fibroblasts. At present, the size of the pixels corresponds an area several times larger than that of a single cell, but by 
optimizing processing conditions downscaling to reach dimensions on the order of a single cell should be possible.

The number of novel biomaterials intended for tissue engineering and implantation is growing steadily, and PEDOT has emerged as one of the most promising for electronic control of cell behaviour. The work presented in this thesis shows that modulation of cellular events such as adhesion, differentiation and detachment can be controlled using PEDOT electrodes. Future development to meet requirements from the field of cell biology includes use of 3D substrates and more complex material combinations to better mimic the situation cells face in vivo. One solution would be to prepare matrices similar to the one used in Paper VI for electropolymerisation with different counter ions in different pixels. Patterns of pixels with varying surface chemistry could thus be prepared. By downscaling, microscale control could be achieved. All in all, organic electronic devices are promising tools for communication and interactions with biological systems. 


\section{REFERENCES}

[1] J. Bardeen, W. H. Brattain, Phys Rev. 1948, 74, 230.

[2] A. G. MacDiarmid, Angew. Chem. Int. Ed. 2001, 40, 2581.

[3] C. K. Chiang, C. R. Fincher, Y. W. Park, A. J. Heeger, H. Shirakawa, E. J. Louis, G. S. C, A. G. MacDiarmid, Phys. Rev. Lett. 1977, 39, 1098.

[4] G. Li, V. Shrotriya, J. Huang, Y. Yao, T. Moriarty, K. Emery, Y. Yang, Nat. Mater. 2005, 4, 864.

[5] H. Klauk, Chem. Soc. Rev. 2010, 39, 2643.

[6] J. T. Mabeck, G. G. Malliaras, Anal. Bioanal. Chem. 2006, 384, 343.

[7] M. R. Abidian, D. H. Kim, D. C. Martin, Adv. Mater. 2006, 18, 405.

[8] X. Cui, J. A. Wiler, M. Dzaman, R. A. Altschuler, D. C. Martin, Biomaterials 2003, 24, 777.

[9] C. E. Schmidt, V. R. Shastri, J. P. Vacanti, R. Langer, Proc. Natl. Acad. Sci. USA 1997, 94, 8948.

[10] D. T. Simon, S. Kurup, K. C. Larsson, R. Hori, K. Tybrandt, M. Goiny, E. W. H. Jager, M. Berggren, B. Canlon, A. Richter-Dahlfors, Nat. Mater. 2009, 8, 742.

[11] K. Svennersten, M. H. Bolin, E. W. H. Jager, M. Berggren, A. RichterDahlfors, Biomaterials 2009, 30, 6257.

[12] M. H. Bolin, K. Svennersten, D. Nilsson, A. Sawatdee, E. W. H. Jager, A. Richter-Dahlfors, M. Berggren, Adv. Mater. 2009, 21, 4379.

[13] M. S. Hybertsen, S. G. Louie, Phys. Rev. B 1986, 34, 5390.

[14] C. S. Yannoni, T. C. Clarke, Phys. Rev. Lett. 1983, 51, 1191.

[15] M. Fahlman, W. R. Salaneck, Surf. Sci. 2002, 500, 904.

[16] M. Kobashi, H. Takeuchi, Macromolecules 1998, 31, 7273.

[17] H. Sirringhaus, P. J. Brown, F. R. H, N. M. M, B. K, L.-V. B. M. W, A. J. H. Spiering, R. A. J. Janssen, E. W. Meijer, P. Herwig, D. M. de Leeuw, Nature 1999, 401, 685.

[18] H. Bronstein, Z. Chen, R. S. Ashraf, W. Zhang, J. Du, J. R. Durrant, P. Shakya Tuladhar, K. Song, S. E. Watkins, Y. Geerts, M. M. Wienk, R. A. J. Janssen, T. Anthopoulos, H. Sirringhaus, M. Heeney, I. McCulloch, J. Am. Chem. Soc. 2011, 133, 3272.

[19] A. J. Epstein, J. M. Ginder, F. Zuo, R. W. Bigelow, H.-S. Woo, D. B. Tanner, A. F. Richter, W.-S. Huang, A. G. MacDiarmid, Synthetic Met. 1987, 18, 303. 
[20] J. Mei, D. H. Kim, A. L. Ayzner, M. F. Toney, Z. Bao, J. Am. Chem. Soc. 2011, 133, 20130.

[21] R. Noriega, J. Rivnay, K. Vandewal, F. P. V. Koch, N. Stingelin, P. Smith, M. F. Toney, A. Salleo, Nat Mater 2013, 12, 1038.

[22] J. L. Brédas, B. Thémans, J. G. Fripiat, J. M. André, Phys. Rev. $B$ 1984, 29, 6761.

[23] A. Miller, E. Abrahams, Phys. Rev. 1960, 120, 745.

[24] H. Bässler, Phys. Status Solidi B 1993, 175, 15.

[25] A. G. MacDiarmid, A. J. Heeger, Synthetic Met. 1980, 1, 101.

[26] J. Heinze, B. A. Frontana-Uribe, S. Ludwigs, Chem. Rev. 2010, 110, 4724.

[27] N. K. Guimard, N. Gomez, C. E. Schmidt, Prog. Polym. Sci. 2007, 32, 876.

[28] B. Krische, M. Zagorska, Synthetic Met. 1989, 28, 257.

[29] R. J. Mortimer, A. L. Dyer, J. R. Reynolds, Displays 2006, 27, 2.

[30] P. R. Somani, S. Radhakrishnan, Mat. Chem. Phys. 2002, 77, 117.

[31] P. Andersson, R. Forchheimer, P. Tehrani, M. Berggren, Adv. Funct. Mater. 2007, 17, 3074.

[32] H. W. Heuer, R. Wehrmann, S. Kirshmeyer, Adv. Funct. Mater. 2002, 12, 89.

[33] Q. Pei, O. Inganäs, J. Phys. Chem. 1992, 96, 10507.

[34] M. R. Gandhi, P. Murray, G. M. Spinks, G. G. Wallace, Synthetic Met. 1995, 73, 247.

[35] E. W. H. Jager, E. Smela, O. Inganäs, Science 2000, 290, 1540.

[36] P. M. George, D. A. LaVan, J. A. Burdick, C. Y. Chen, E. Liang, R. Langer, Adv. Mater. 2006, 18, 577.

[37] A. Ramanavičius, A. Kaušaitè, A. Ramanavičienè, Sens. Actuat. B: Chem. 2005, 111-112, 532.

[38] G. Heywang, F. Jonas, Adv. Mater. 1992, 4, 116.

[39] L. B. Groenendaal, F. Jonas, D. Freitag, H. Pielartzik, J. R. Reynolds, Adv. Mater. 2000, 12, 481.

[40] Q. Pei, G. Zuccarello, M. Ahlskog, O. Inganäs, Polymer 1994, 35, 1347.

[41] X. Crispin, F. L. E. Jakobsson, A. Crispin, P. C. M. Grim, P. Andersson, A. Volodin, C. van Haesendonck, M. Van der Auweraer, W. R. Salaneck, M. Berggren, Chem. Mater. 2006, 18, 4354.

[42] M. Asplund, E. Thaning, J. Lundberg, A. C. Sandberg-Nordqvist, B. Kostyszyn, O. Inganäs, H. von Holst, Biomed. Mater. 2009, 4, 1.

[43] H. Yamoto, M. Ohwa, W. Wernet, J. Electroanal. Chem. 1995, 397, 163.

[44] D. J. Macaya, M. Nikolou, S. Takamatsu, J. T. Mabeck, R. M. 
Owens, G. G. Malliaras, Sens. Actuat. B: Chem. 2007, 123, 374.

[45] A. Herland, K. M. Persson, V. Lundin, M. Fahlman, M. Berggren, E. W. H. Jager, A. I. Teixeira, Angew. Chem. Int. Ed. 2011, 50, 12529.

[46] A. Gumus, J. P. Califano, A. M. D. Wan, J. Huynh, C. A. ReinhartKing, G. G. Malliaras, Soft Matter 2010, 6, 5138.

[47] K. Tybrandt, K. C. Larsson, S. Kurup, D. T. Simon, P. Kjäll, J. Isaksson, M. Sandberg, E. W. H. Jager, A. Richter-Dahlfors, M. Berggren, Adv. Mater. 2009, 21, 4442.

[48] A. O. Patil, Y. Ikenoue, F. Wudl, A. J. Heeger, J. Am. Chem. Soc. 1987, 109, 1858.

[49] A. O. Patil, Y. Ikenoue, N. Basescu, N. Colaneri, J. Chen, F. Wudl, A. J. Heeger, Synthetic Met. 1987, 20, 151.

[50] C. A. Cutler, M. Bouguettaya, T.-S. Kang, J. R. Reynolds, Macromolecules 2005, 38, 3068.

[51] O. Stéphan, P. Schottland, P.-Y. Le Gall, C. Chevrot, C. Mariet, M. Carrier, J. Electroanal. Chem. 1998, 443, 217.

[52] R. H. Karlsson, A. Herland, M. Hamedi, J. A. Wigenius, A. Åslund, X. Liu, M. Fahlman, O. Inganäs, P. Konradsson, Chem. Mater. 2009, 21, 1815.

[53] A. A. Pud, Synthetic Met. 1994, 66, 1.

[54] Q. Pei, O. Inganäs, J. Phys. Chem. 1993, 97, 6034.

[55] P. G. Pickup, Electrochemistry of Electronically Conducting Polymer Films, Kluwer Academic/Plenum Publishers, New York, 1999.

[56] E. Smela, N. Gadegaard, J. Phys. Chem. B 2001, 105, 9395.

[57] X. Ren, P. G. Pickup, J. Phys. Chem. 1993, 97, 5356.

[58] J. Isaksson, C. Tengstedt, M. Fahlman, N. Robinson, M. Berggren, Adv. Mater. 2004, 16, 316.

[59] X. Wang, M. Berggren, O. Inganäs, Langmuir 2008, 24, 5942.

[60] L. Xu, W. Chen, A. Mulchandani, Y. Yan, Angew. Chem. Int. Ed. 2005, 44, 6009.

[61] A. Azioune, M. M. Chehimi, B. Miksa, T. Basinska, S. Slomkowski, Langmuir 2002, 18, 1150.

[62] N. A. Patankar, Langmuir 2004, 20, 8209.

[63] B. Garner, A. Georgevich, A. J. Hodgson, L. Liu, W. G. G, J. Biomed. Mater. Res. 1999, 44, 121.

[64] C. Carlberg, X. Chen, O. Inganäs, Solid State lonics 1996, 85, 73.

[65] X. Chen, K.-Z. Xing, O. Inganäs, Chem. Mater. 1996, 8, 2439.

[66] L. Bay, T. Jacobsen, S. Skaarup, K. West, J. Phys. Chem. B 2001, 105, 8492.

[67] M. J. M. Jafeen, M. A. Careem, S. Skaarup, Ionics 2009, 16, 1.

[68] E. Smela, O. Inganäs, I. Lundström, Science 1995, 268, 1735. 
[69] R. H. Baughman, Synthetic Met. 1996, 78, 339.

[70] J.-M. Pernaut, J. R. Reynolds, J. Phys. Chem. B 2000, 104, 4080.

[71] G. Buzsáki, Nat. Neurosci. 2004, 7, 446.

[72] A. Star, E. Tu, J. Niemann, J.-C. P. Gabriel, C. S. Joiner, C. Valcke, Proc. Natl. Acad. Sci. USA 2006, 103, 921.

[73] J. D. Newman, A. P. F. Turner, Biosens. Bioelectron. 2005, 20, 2435.

[74] M. Berggren, A. Richter-Dahlfors, Adv. Mater. 2007, 19, 3201.

[75] D. H. Kim, S. M. Richardson-Burns, J. L. Hendricks, C. Sequera, D.

C. Martin, Adv. Funct. Mater. 2007, 17, 79.

[76] D.-H. Kim, J. A. Wiler, D. J. Anderson, D. R. Kipke, D. C. Martin, Acta Biomater. 2010, 6, 57.

[77] P. Åsberg, O. Inganäs, Biosens. Bioelectron. 2003, 19, 199.

[78] T. Aoki, M. Tanino, K. Sanui, N. Ogata, K. Kumakura, Biomaterials 1996, 17, 1971.

[79] D. Khodagholy, T. Doublet, P. Quilichini, M. Gurfinkel, P. Leleux, A. Ghestem, E. Ismailova, T. Herve, S. E. B. Sanaur, C. Bernard, G. G. Malliaras, Nat. Comm. 2013, 4, 1575.

[80] K. A. Ludwig, J. D. Uram, J. Yang, D. C. Martin, D. R. Kipke, J. Neural Eng. 2006, 3, 59.

[81] C. A. Haynes, W. Norde, Colloid. Surface. B 1994, $2,517$.

[82] M. J. Higgins, P. J. Molino, Z. Yue, G. G. Wallace, Chem. Mater. 2012, 24, 828.

[83] P. Roach, D. Farrar, C. C. Perry, J. Am. Chem. Soc. 2006, 128, 3939.

[84] Y. Koc, A. J. de Mello, G. McHale, M. I. Newton, P. Roach, N. J. Shirtcliffe, Lab Chip 2008, 8, 582.

[85] D. T. Kim, H. W. Blanch, C. J. Radke, Langmuir 2002, 18, 5841.

[86] G. F. Khan, W. Wernet, Thin Solid Films 1997, 300, 265.

[87] Y.-X. Wang, J. L. Robertson, W. B. J. Spillman, R. O. Claus, Pharmaceut. Res. 2004, 21, 1362.

[88] Y.-H. Zhao, B.-K. Zhu, L. Kong, Y.-Y. Xu, Langmuir 2007, 23, 5779.

[89] R. Michel, S. Pasche, M. Textor, D. G. Castner, Langmuir 2005, 21, 12327.

[90] Y. Zhang, Y. Fung, H. Sun, D. Zhu, S. Yao, Sens. Actuat. B:Chem. 2005, 108, 933.

[91] L.-P. Wang, W. Wang, L. Di, Y.-N. Lu, J.-Y. Wang, Colloid. Surface. B 2010, 80, 72.

[92] Z. Zhang, Y. Liang, P. Liang, C. Li, S. Fang, Polym. Int. 2011, 60, 703.

[93] M. D. Pierschbacher, E. Ruoslahti, Proc. Natl. Acad. Sci. USA 1984, $81,5985$. 
[94] A. Curtis, C. Wilkinson, Biomaterials 1997, 18, 1573.

[95] J. H. Lee, G. Khang, J. W. Lee, H. B. Lee, J.Colloid Interf. Sci. 1998, 205, 323.

[96] J. E. Wong, R. Langer, D. E. Ingber, Proc. Natl. Acad. Sci. USA 1994, 91, 3201.

[97] J. Y. Lee, E.-D. Jeong, C. W. Ahn, J.-W. Lee, Synthetic Met. 2013, 185-186, 66.

[98] A. Gelmi, M. J. Higgins, G. G. Wallace, Biomaterials 2010, 31, 1974.

[99] J. H. Collier, J. P. Camp, T. W. Hudson, C. E. Schmidt, J. Biomed. Mater. Res. 1999, 50, 574.

[100] C. Saltó, E. Saindon, M. Bolin, A. Kanciurzewska, M. Fahlman, E. W. H. Jager, P. Tengvall, E. Arenas, M. Berggren, Langmuir 2008, 24, 14133.

[101] R. O. Hynes, Science 2009, 326, 1216.

[102] M. Goldberg, R. Langer, X. Jia, J. Biomater. Sci. 2007, 18, 241.

[103] S. V. Vinogradov, T. K. Bronich, A. V. Kabanov, Adv. Drug Deliver. Rev. 2002, 54, 135.

[104] W. Jiang, R. Gupta, M. Deshpande, S. Schwendeman, Adv. Drug Deliver. Rev. 2005, 57, 391.

[105] K. Zhang, X. Y. Wu, Biomaterials 2004, 25, 5281.

[106] B. C. Thompson, S. E. Moulton, J. Ding, R. Richardson, A. Cameron, S. O'Leary, G. G. Wallace, G. M. Clark, J.Control. Release 2006, 116, 285.

[107] R. Wadhwa, C. F. Lagenaur, X. T. Cui, J. Control. Release 2006, 110, 531.

[108] H. Xu, C. Wang, C. Wang, J. Zoval, M. Madou, Biosens. Bioelectron. 2006, 21, 2094.

[109] G. Jeon, S. Y. Yang, J. Byun, J. K. Kim, Nano Lett. 2011, 11, 1284.

[110] J. Isaksson, P. Kjäll, D. Nilsson, N. Robinson, M. Berggren, A.

Richter-Dahlfors, Nat. Mater. 2007, 6, 673.

[111] C. D. Tidwell, S. I. Ertel, B. D. Ratner, Langmuir 1997, 3404.

[112] R. Biran, M. D. Noble, P. A. Tresco, J. Biomed. Mater. Res. 1999, 46, 150.

[113] A. I. Teixeira, S. Ilkhanizadeh, J. A. Wigenius, J. K. Duckworth, O. Inganäs, O. Hermanson, Biomaterials 2009, 30, 4567.

[114] D. E. Discher, Science 2005, 310, 1139.

[115] P. Clark, P. Connolly, G. R. Moores, J. Cell Sci. 1992, 103, 287.

[116] C. J. Bettinger, R. Langer, J. T. Borenstein, Angew. Chem. Int. Ed. 2009, 48, 5406.

[117] K. Alberti, R. E. Davey, K. Onishi, S. George, K. Salchert, F. P. Seib, M. Bornhäuser, T. Pompe, A. Nagy, C. Werner, P. W. Zandstra, Nat. 
Meth. 2008, 5, 645.

[118] A. Kotwal, C. E. Schmidt, Biomaterials 2001, 22, 1055.

[119] K. Svennersten, M. Berggren, A. Richter-Dahlfors, E. W. H. Jager, Lab Chip 2011, 11, 3287.

[120] K. J. Gilmore, M. Kita, Y. Han, A. Gelmi, M. J. Higgins, S. E. Moulton,

G. M. Clark, R. Kapsa, G. G. Wallace, Biomaterials 2009, 30, 5292.

[121] C. Waymouth, In vitro 1974, 10, 97.

[122] H. Hatakeyama, A. Kikuchi, M. Yamato, T. Okano, Biomaterials 2007, 28, 3632.

[123] A. Ito, K. Ino, T. Kobayashi, H. Honda, Biomaterials 2005, 26, 6185.

[124] X. Lu, P. Zhong, ARLO 2005, 6, 195.

[125] E. W. L. Chan, S. Park, M. N. Yousaf, Angew. Chem. Int. Ed. 2008, 47, 6267.

[126] R. Inaba, A. Khademhosseini, H. Suzuki, J. Fukuda, Biomaterials 2009, 30, 3573.

[127] X. Jiang, R. Ferrigno, M. Mrksich, G. M. Whitesides, J. Am. Chem. Soc. 2003, 125, 2366.

[128] O. Guillaume-Gentil, Y. Akiyama, M. Schuler, C. Tang, M. Textor, M. Yamato, T. Okano, J. Vörös, Adv. Mater. 2008, 20, 560.

[129] K. M. Persson, R. Karlsson, K. Svennersten, S. Löffler, E. W. H. Jager, A. Richter-Dahlfors, P. Konradsson, M. Berggren, Adv. Mater. 2011, 23, 4403.

[130] W.-S. Yeo, M. Mrksich, Langmuir 2006, 22, 10816.

[131] R. J. Doyle, Microbes Infect. 2000, 2, 391.

[132] B. Gottenbos, D. W. Grijpma, H. C. van der Mei, J. Feijen, H. J.

Busscher, J. Antimicrob. Chemoth. 2001, 48, 7.

[133] B. Gottenbos, H. J. Busscher, H. C. van der Mei, P. Nieuwenhuis, J. Mater. Sci. 2002, 13, 717.

[134] R. D. Boyd, J. Verran, M. V. Jones, M. Bhakoo, Langmuir 2002, 18, 2343.

[135] J. Wei, D. B. Ravn, L. Gram, P. Kingshott, Colloid. Surface. B. 2003, 32, 275.

[136] J. W. Costerton, K. J. Chang, G. G. Geesey, T. I. Ladd, M. Dasgupta, T. J. Marrie, Annu. Rev. Microbiol. 1987, 41, 435.

[137] J. W. Costerton, P. S. Stewart, E. P. Greenberg, Science 1999, 284, 1318.

[138] Z. Ren, T. E. Ward, J. M. Regan, Environ. Sci. Technol. 2007, 41, 4781.

[139] G. Cheng, Z. Zhang, S. Chen, J. D. Bryers, S. Jiang, Biomaterials 2007, 28, 4192.

[140] A. Roosjen, H. C. van der Mei, H. J. Busscher, W. Norde, Langmuir 
2004, 20, 10949.

[141] A. Terada, A. Yuasa, T. Kushimoto, S. Tsuneda, A. Katakai, M. Tamada, Microbiology 2006, 152, 3575.

[142] D. Cunliffe, C. de las Heras Alarcón, V. Peters, J. R. Smith, C. Alexander, Langmuir 2003, 19, 2888.

[143] T. P. Schaer, S. Stewart, B. B. Hsu, A. M. Klibanov, Biomaterials 2012, 33, 1245.

[144] B. Teixeira-Dias, L. J. del Valle, D. Aradilla, F. Estrany, C. Alemán, Macromol. Mater. Eng. 2011, 297, 427.

[145] Y. H. Ha, N. Nikolov, S. K. Pollack, J. Mastrangelo, B. D. Martin, R. Shashidhar, Adv. Funct. Mater. 2004, 14, 615.

[146] A. Mohammadi, M. A. Hasan, B. Liedberg, I. Lundström, W. R. Salaneck, Synthetic Met. 1986, 14, 189.

[147] B. Winther-Jensen, K. West, Macromolecules 2004, 37, 4538.

[148] M. Fabretto, J.-P. Autere, D. Hoglinger, S. Field, P. Murphy, Thin Solid Films 2011, 519, 2544.

[149] B. Winther-Jensen, D. W. Breiby, K. West, Synthetic Met. 2005, 152, 1.

[150] M. Fabretto, K. Zuber, C. Hall, P. Murphy, H. J. Griesser, J. Mater. Chem. 2009, 19, 7871.

[151] M. Mueller, M. Fabretto, D. Evans, P. Hojati-Talemi, C. Gruber, P. Murphy, Polymer 2012, 53, 2146.

[152] M. H. Bolin, K. Svennersten, X. Wang, I. S. Chronakis, A. RichterDahlfors, E. W. H. Jager, M. Berggren, Sens. Actuat. B: Chem. 2009, 142, 451.

[153] S. Sadki, P. Schottland, N. Brodie, G. Sabouraud, Chem. Soc. Rev. 2000, 29, 283.

[154] E. M. Genies, G. Bidan, A. F. Diaz, J. Electroanal. Chem. 1983, 149, 101.

[155] I. Villareal, E. Morales, J. L. Acosta, Polymer 2001, 42, 3779.

[156] A. R. Hillman, E. F. Mallen, J. Electroanal. Chem. 1987, 220, 351.

[157] F.-B. Li, W. J. Albery, Langmuir 1992, 8, 1645.

[158] Z. S. Zhao, P. G. Pickup, Faraday Trans. 1994, 90, 3097.

[159] F. Chao, M. Costa, C. Tian, Synthetic Met. 1993, 53, 127.

[160] N. Sakmeche, J.-J. Aaron, S. aeiyach, P.-C. Lacaze, Electrochim. Acta 2000, 45, 1.

[161] Y. Li, J. Yang, J. Appl. Polym. Sci. 1997, 65, 2739.

[162] L. F. Warren, D. P. Anderson, J. Electrochem. Soc. 1987, 134, 101.

[163] T. F. Otero, J. Rodriguez, E. Angulo, C. Santamaria, Synthetic Met. 1991, 41, 2831.

[164] J. Unsworth, P. C. Innis, B. A. Lunn, Z. Jin, G. P. Norton, Synthetic 
Met. 1992, 53, 59.

[165] P. H. Aubert, L. Groenendaal, F. Louwet, L. Lutsen, D. Vanderzande, G. Zotti, Synthetic Met. 2002, 126, 193.

[166] N. Sakmeche, S. Aeiyach, J.-J. Aaron, M. Jouini, J. C. Lacroix, P.-C. Lacaze, Langmuir 1999, 15, 2566.

[167] R. Schweiss, J. F. Lübben, D. Johannsmann, W. Knoll, Electrochim. Acta 2005, 1.

[168] M. Asplund, H. von Holst, O. Inganäs, Biointerphases 2008, 3, 83.

[169] X. Du, Z. Wang, Electrochim. Acta 2003, 48, 1713.

[170] V. Lundin, A. Herland, M. Berggren, E. W. H. Jager, A. I. Teixeira, PLOS ONE 2011, 6, e18624.

[171] R. A. Green, N. H. Lovell, L. A. Poole-Warren, Acta Biomater. 2010, 6, 63.

[172] K. Meerholz, J. Heinze, Synthetic Met. 1993, 55, 5040.

[173] K. Meerholz, J. Heinze, Electrochim. Acta 1996, 41, 1839. 
PART 2

THE PAPERS 



\section{Papers}

The articles associated with this thesis have been removed for copyright reasons. For more details about these see:

http://urn.kb.se/resolve?urn=urn:nbn:se:liu:diva-106254 